\title{
Numerical Investigation on Gas Production Performance in Methane Hydrate of Multilateral Well under Depressurization in Krishna-Godavari Basin
}

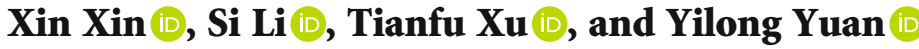 \\ Key Laboratory of Groundwater Resources and Environment, Ministry of Education, Jilin University, Changchun 130021, China \\ Correspondence should be addressed to Xin Xin; xxxx@jlu.edu.cn
}

Received 25 March 2021; Revised 19 June 2021; Accepted 26 July 2021; Published 20 August 2021

Academic Editor: Bo Li

Copyright (C) 2021 Xin Xin et al. This is an open access article distributed under the Creative Commons Attribution License, which permits unrestricted use, distribution, and reproduction in any medium, provided the original work is properly cited.

\begin{abstract}
Nature gas hydrate is a new kind of clean and potential resources. Depressurization is regarded as the most effective and promising hydrate production technology. One of the key points in improving the gas production effectiveness of depressurization is whether pressure gradient could transmit in strata effectively. Single well method is widely used in hydrate exploit which is circumscribed in expanding the range of hydrate decomposition. Consequently, the well structure and production strategy needs to be optimized for improving the gas recovery efficiency. The multilateral well technology is proposed for increasing the gas productivity of the reservoir greatly by increasing the multilateral branches. In this paper, we established a numerical simulation model based on the geological data NGHP-02-16 site in the KG basin to evaluate the gas production performance of the reservoir by depressurization. It mainly focuses on investigating the gas production performance of multilateral wells with different combinations of geometric parameters of multilateral branches, such as different dip angle, numbers, and spacing of lateral branches. The result shows that the multilateral well method can effectively increase the gas production rate with the water production rate increase slightly. The cumulative gas production volume of a single vertical well is about $2.85 \times 10^{6} \mathrm{~m}^{3}$, while it is of the multilateral well can reach $4.18 \times 10^{6} \mathrm{~m}^{3}$ during a one-year production. The well interference, the effective influence radius of each multilateral branch, and the vertical depth of the lateral branch are the main factors which affect the gas production efficiency of the multilateral well. The optimization of the geometric parameters of lateral should consider not only the gas production efficiency but also the well interference between the lateral branches.
\end{abstract}

\section{Introduction}

Nature gas hydrate (NGH), an ice-like crystalline compound, can exist steadily in low-temperature and high-pressure conditions $[1,2]$. This gas hydrate molecule consisting of a lattice of one type of molecule trapping and containing a second type of molecule (such as $\mathrm{CH}_{4}, \mathrm{C}_{2} \mathrm{H}_{6}, \mathrm{C}_{3} \mathrm{H}_{8}$, and $\mathrm{C}_{4} \mathrm{H}_{10}$ ). At standard pressure and temperature, a methane hydrate molecule contains approximately 160 volumes of methane for each volume of water $[3,4]$. This energy is regarded as a clean and potential resources.

The methane hydrate would decompose into gas and water when the three-phase equilibrium of gas hydrate was broken $[5,6]$. Consequently, there are four gas production methods including depressurization, thermal stimulation, inhibitor injection, and gas replacement, of which depressurization was regarded as the most effective and promising one [7-9]. The depressurization method is promoting the methane hydrate dissociation into gas and water by decreasing the local pressure of the layer below the phase equilibrium curve of gas hydrate [10]. The gas production effectiveness under depressurization depends on whether pressure gradient could transmit in strata effectively and whether there is enough heat energy to support the dissociation of gas hydrates [11]. Enlarge the area of depressurized discharge is one of the key factors in increasing the gas production efficiency [12].

Up to now, the single well method is widely used in hydrate exploitation under depressurization. However, the single well method has its limitations on actual gas hydrate 
production. Take a single vertical well for example. This well has a limited area contact with the hydrate reservoir which is unfavorable for long-term production. Compare with the single well method, the multilateral wells are proposed for it has more contact area with reservoir and effectively increase production well productivity under the same depressurization [12-14]. The concept of multilateral wells originated from reservoir production. The number of multilateral well completions has increased substantially in the last several years due to advances in directional drilling and completion systems [15]. Up to now, there were more than 8000 multilateral wells all over the world and obtained a remarkable economic profit [16]. The technique for multilateral well drilling in the offshore field faces more challenges than drilling in the onshore field [17]. Thus, the offshore drilling for the multilateral well was few in actual production. In 2020, Guo et al. developed a multilateral ultrashort radius drilling technology for offshore oilfields assisted by the technologies of casing program design, branching point selection, wellbore trajectory design, and drilling parameter control technology and also first applied this drilling technology in China offshore oilfields fulfilled the kick-off operation successfully [18]. This technology offered the possibility for applying the multilateral wells technology in gas hydrate production.

The multilateral wells have been introduced into gas hydrate production recently. In 2010, Wilson et al. found that added several branches on the single vertical well can improve gas production obviously during the prediction of gas hydrate reserves in the North Slope of Alaska [19]. In 2018, Chen et al. proposed a novel exploitation technique named large borehole with multilateral branches combined moderate sand control exploitation technique [20]. In the same year, Wan et al. invented a method for productivity and reservoir stability analysis of hydrate depressurization in multilateral wells. It provides an effective description method for quantifying production capacity and stability analysis of multilateral wells [21]. In 2019, Li et al. proposed a methodology of hydrate production based on multilateral wells. It can exploit the gas hydrate by thermal stimulation and depressurization through the multilateral wells which realized the circular utilization of energy in the hydrate reservoir [22]. Li et al. pointed out that the application of complex structure Wells such as extended-reach horizontal well and multilateral well should be considered in the research of hydrate exploitation [23]. In 2020, Mao et al. compared the methane hydrate productivity of a single vertical well and a vertically distributed two-branch horizontal well by experimental simulation under depressurization. The two-branch horizontal well shows the advantage of stability in longterm gas production [24]. The above investigations have properly promoted the development of the application of multilateral well in NGH production. Nevertheless, the optimal combination of geometric parameters and gas and water production performance of multilateral well in gas hydrate production were not discussed a lot.

Generally, the multilateral well was divided into two types named horizontal multilateral well and vertical multilateral well according to the shape of the main well. Determining the optimal combination of geometric parameters

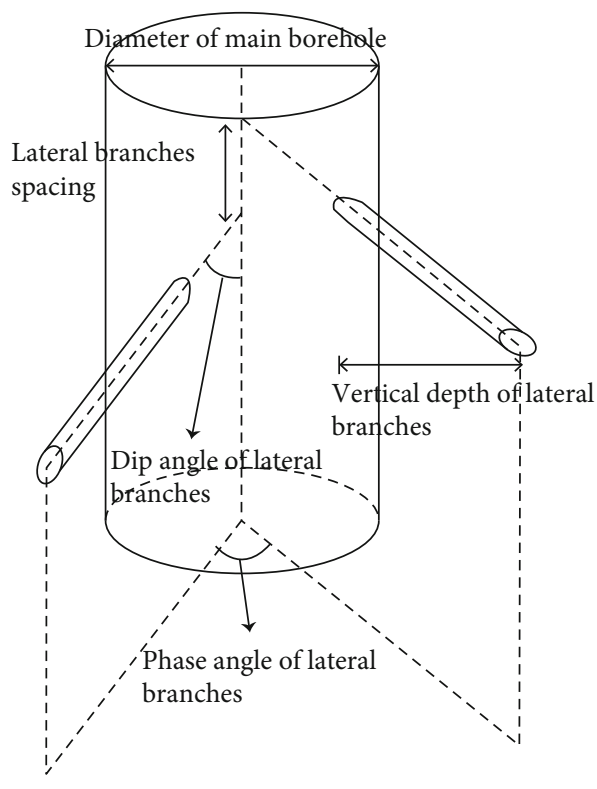

FIgURE 1: Schematic diagram for explanation of morphological parameters of multilateral branches [27].

and manner of distribution of multilateral branches is vital for gas hydrate exploitation $[25,26]$. As is shown in Figure 1, the geometric parameters of multilateral branches mainly include the phase angle, the dip angle, the lateral branches spacing, the diameter, and the horizontal displacement of the lateral [27].

With a large demand but limited resources, India embarked on exploring the exist of National Gas Hydrate Program (NGHP). Up to now, India's National Gas Hydrate Program has steered two logging and coring expeditions [28]. The National Gas Hydrate Program 01 Expedition (2006) found that most of the recovered gas hydrate was characterized as a fracture-filling material in fine-grained (mostly clay-rich) sediments [29]. Subsequently, the National Gas Hydrate Program 02 Expedition (NGHP-02) operated in 2015. This expedition investigated four areas (Area A, Area B, Area C, and Area D) from northeast to southwest in the Krishna-Godavari Basin [30, 31], and a high saturation of gas hydrate exists in the eastern continental margin of India especially in area B [32]. This area is deep-water channel-levee-fan systems with gas hydrate at high saturation existed in silt to sandy sediments. However, the total thickness of the hydrate layer is small which is unsuitable to exploit by using a single vertical well method. So, the multilateral well could be considered in the production at this area.

In this paper, we take the Site NGHP-02-16 in Area B of the Krishna-Godavari Basin as the aim area. We extensively used the borehole geophysical logging, seismic interpretation, and core analyses at Site NGHP-02-16 and, then, established a geological model for investigating the gas production performance by using a single vertical well under depressurization from sand-rich gas-hydrate reservoirs in the ultradeepwater environment as a fundamental 


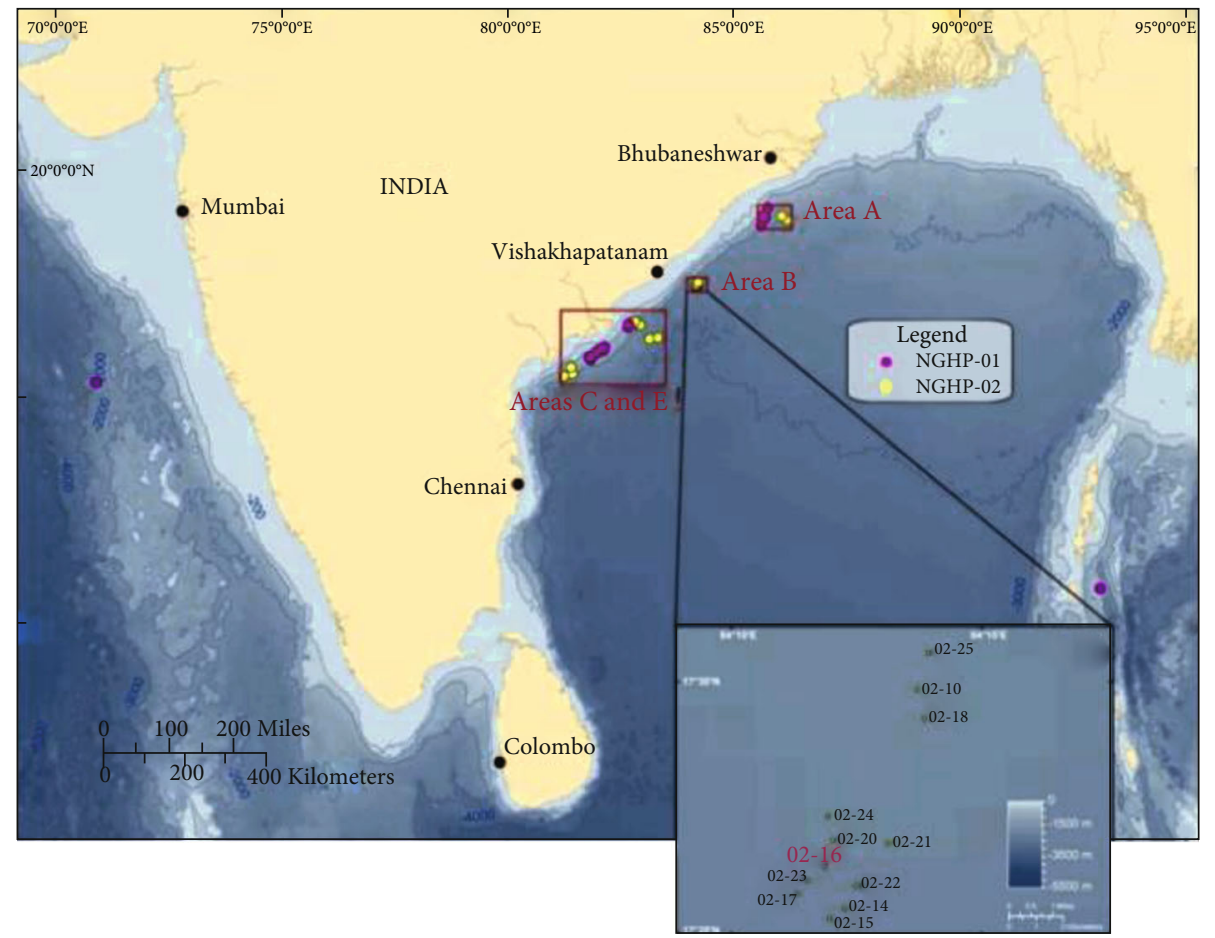

FIgURe 2: Location of Sites NGHP-02-16 (Area B), offshore India [35].

comparison. Furthermore, we developed the multilateral well models based on the single vertical well to investigate the effect of geometric parameters and emplacing manners of production interval on the production performance. This work can provide useful suggestions for the future gas production.

\section{Simulation Model}

2.1. Geological Setting. The study area is located on the Krishna-Godavari Basin in the southeast of India which is an important petroliferous basin with abundant organic matter contained. This basin was divided into four geographic areas (Area A, B, C, and D) during the NGHP-02 expedition (Figure 2) according to seismic data sets in which Area B and $\mathrm{C}$ were deep-water channel-levee-fan systems with gas hydrate at high saturation [33,34]. The geological model focus on site NGHP-02-16 in Area B. Water depth of this location is $2546.5 \mathrm{~m}$. However, site NGHP-02-16 (2546.5 m) is much deeper than the test sites at the eastern Nankai Trough $(1000 \mathrm{~m})$ and the South China Sea $(1266 \mathrm{~m})$ which is defined as ultradeepwater. Based on the lithological structure, the sediment is divided into five units (Figure 3). Unit 1 includes high porosity mud-rich sediments. Unit 2 contains mud-rich sediment and fracture-filling gas hydrates with low concentration. Unit 3 is composed of uniform marine muds. Reservoir of Unit 4 consisting of alternating fine gas hydratebearing sand unit and mud unit which modeled as methane hydrate concentrated zones (MHCZ). The thickness of the target MHCZ is $24 \mathrm{~m}$ and at the bottom of this unit is water-bearing sand with no gas hydrate. Unit 5 is a section of uniform marine muds with no gas hydrate present [35].

\subsection{Model Setup}

2.2.1. Model Geometry and Spatial Discretization. A cube with a length is $740 \mathrm{~m}$, a breadth is $700 \mathrm{~m}$, and a thickness is $84 \mathrm{~m}$ is employed for the model domain (Figure 4). The thickness of MHCZ is $24 \mathrm{~m}$ (24 grids in $\mathrm{Z}$ direction), and both the overburden and underburden layers are $30 \mathrm{~m}$. The bottom of MHCZ is water-bearing sand whose thickness is $4 \mathrm{~m}$ based on the well logging and core data at this site. The production well with a radius of $0.1 \mathrm{~m}$ is located in the center of the model. And the production interval is $15 \mathrm{~m}$ from the top of MHCZ for isolating from the water-bearing below MHCZ to prevent water production [35].

Figure 5 shows the schematic of the mesh designed in this model. The simulation domain was discretized into $22 \times 18 \times 34$ grids (13464 cells) in $\mathrm{X}, \mathrm{Y}$, and $\mathrm{Z}$ directions. According to Yuan et al., the principal processes occur around the production well within a limited distance during the exploitation [36]. Therefore, the interval of each grid in MHCZ is $1.0 \mathrm{~m}$ along the $\mathrm{z}$-coordinate. Vertical grid size in both overlying and underlying layers is $5 \mathrm{~m}$. The grid size along $\mathrm{X}$ and $\mathrm{Y}$ direction increased with the minimum interval of $4 \mathrm{~m}$ for the key process occurs within 20-30 $\mathrm{m}$ around the production well.

2.2.2. Reservoir Properties and Parameters. According to the data obtained from the field test in Krishna-Godavari Basin, the main modeling parameters and physical properties of NGHP-02-16 site are determined as shown in Table 1. In order to simplify the simulation, layers of the model were regarded as isotropic homogeneity. Key data used to characterize the gas hydrate-bearing units are primarily obtained 


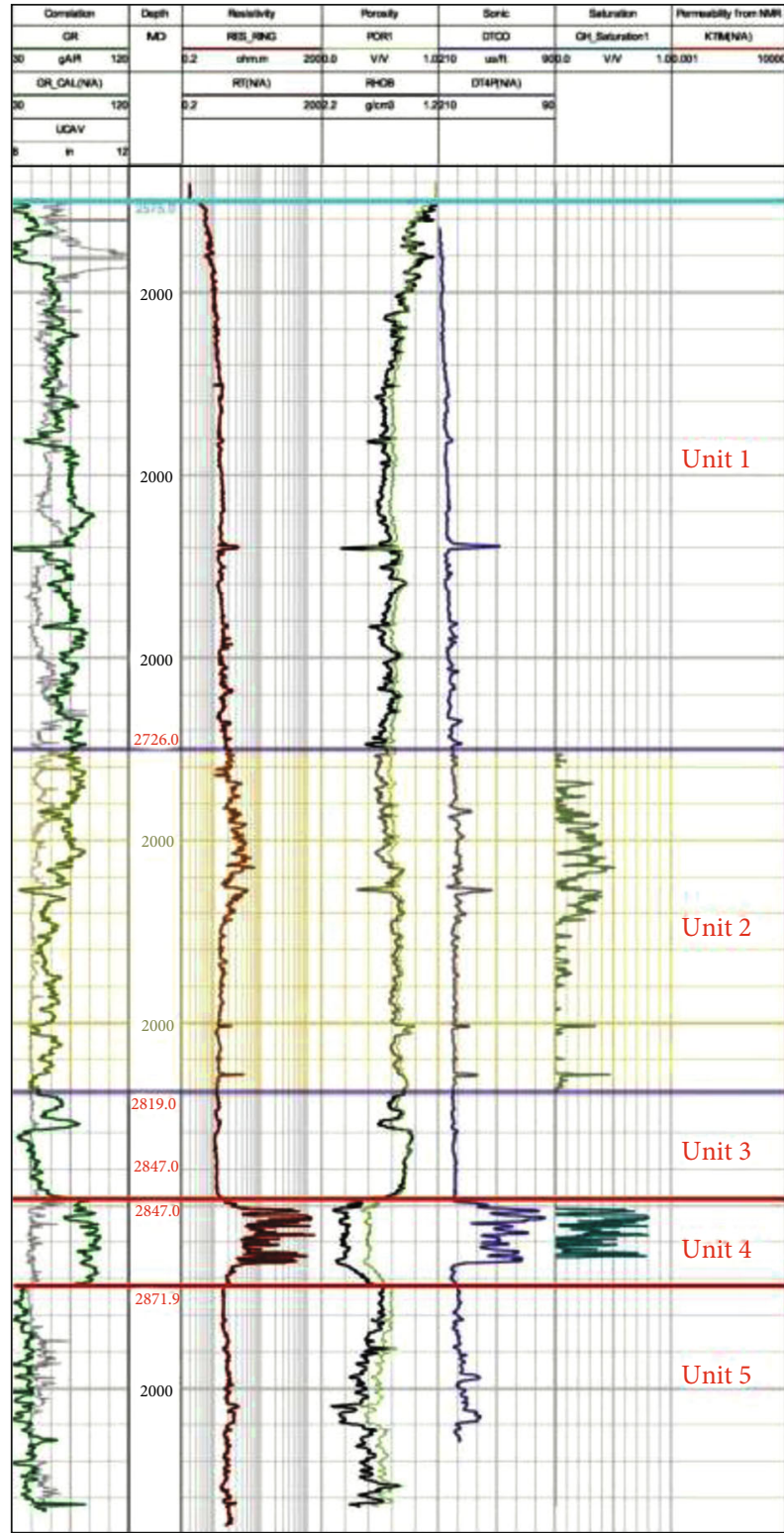

Figure 3: NGHP-02 Area B reservoir composite well log for the Hole NGHP-02-16 [35].

from advanced well log suites acquired at Site NGHP-02-16 [30]. Measured vertical permeability value with Site NGHP02-16 reservoir is in the range from 0.03 to $190 \mathrm{mD}$ [37]. In this simulation, we set permeability at $50 \mathrm{mD}$ in vertical direction and $100 \mathrm{mD}$ in horizontal direction. The porosity in sediment is 0.40 that is determined from the density log. Konno et al. calculated the porosity from the density log data [38], the result shows that the porosity in MHCZ at NGHP02-16 site has a vertical heterogeneity, and the value is in the range from 0.2 to 0.8 . In this simulation, we take the average. The hydrate saturation in MHCZ is calculated by averaging the values in the fine layer of logging data [38]. Figure 6 shows the Depth profiles of effective porosity, hydrate saturation, initial effective and absolute permeabilities, pressure, and temperature around the MHCZ at site NGHP-02-16.
Furthermore, the method used to decompose the solid hydrate was depressurization. And the depressurization processes both in this simulation lasted for 6 days [36]. The wellbore pressure of the production well was decreased from 25.22 MPa to $19.0 \mathrm{MPa}$.

2.2.3. Initial and Boundary Conditions. The seafloor temperature was $1.98^{\circ} \mathrm{C}$, and the geothermal gradient was $0.066^{\circ} \mathrm{C} / \mathrm{m}$. The water salinity was set at $35 \mathrm{ppt}$. 272.8 meters below the seafloor is the top of MHCZ. The hydrate was assumed to exist only in the sand layer, forming homogeneous hydrate-bearing sand, and the initial gas hydrate saturation of the MHCZ was 70\% [38-40]. The initial formation pressure was specified in accordance with the hydrostatic pressure. Initial pressure at the base of MHCZ is $28.79 \mathrm{MPa}$. The entire domain is in an equilibrium state before the depressurization.

The top of the overburden and the bottom of the underburden are designed as constant temperature and pressure boundaries. The boundary with $300 \mathrm{~m}$ around the production well is designed as no flow of fluids and heat exchange boundary to avoid the boundary effects.

2.2.4. The Numerical Simulation Code. We used the TOUGH +HYDRATE simulation software in this study. This code can model the nonisothermal gas release, phase behavior, and flow of fluids and heat under conditions typical of common natural CH4-hydrate deposits. It includes both an equilibrium and a kinetic model of hydrate formation and dissociation. The model can describe all possible hydrate dissociation mechanisms, i.e., depressurization, thermal stimulation, salting-out effects, and inhibitor-induced effects [41].

\section{Results and Analysis}

3.1. Gas and Water Production Behaviors. Figure 7 shows the evolution of the volumetric rate of produced gas at the single vertical well and the evolution of volumetric rates of water production in the well during a one-year production. Early in depressurization is the stage that the wellbore decompresses rapidly so the curves fluctuated greatly (before $t=3 \mathrm{~d}$ ). During $t=3 \mathrm{~d}$ to $t=15 \mathrm{~d}$, the gas hydrate sediment started to decompose because of the significant decrease of borehole pressure so gas and water production increased. In the initial short period (from $t=15 \mathrm{~d}$ to $t=$ $100 \mathrm{~d}$ ), the gas hydrate sediment decomposed along with the production well within limited sediment in vertical direction $(20 \mathrm{~m})$, and the decompose of hydrate is an endothermic proceed results in temperature decline around the well which result in gas production decreased. Due to the effect of the pressure difference, water flows into the production well. At the moment, the hydrate decomposition rate is affected, and the rate of decomposition decreased. From $t=100 \mathrm{~d}$ to $t=365 \mathrm{~d}$ stage, more gas hydrate sediment decomposes quickly. The reasons for this trend may be as follows: in this stage, the decomposition range of hydrate expanded in horizontal direction due to depressurization transmission in MHCZ. Therefore, the decomposition rate of the hydrate reservoir begins to increase. 


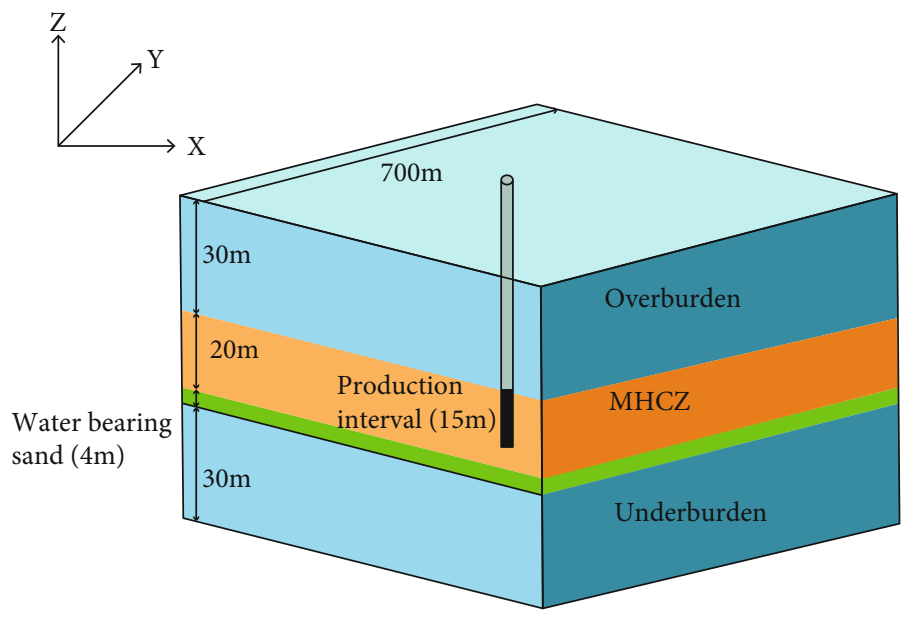

FIgURE 4: The geometry of the simulation domain and the configuration of production well.

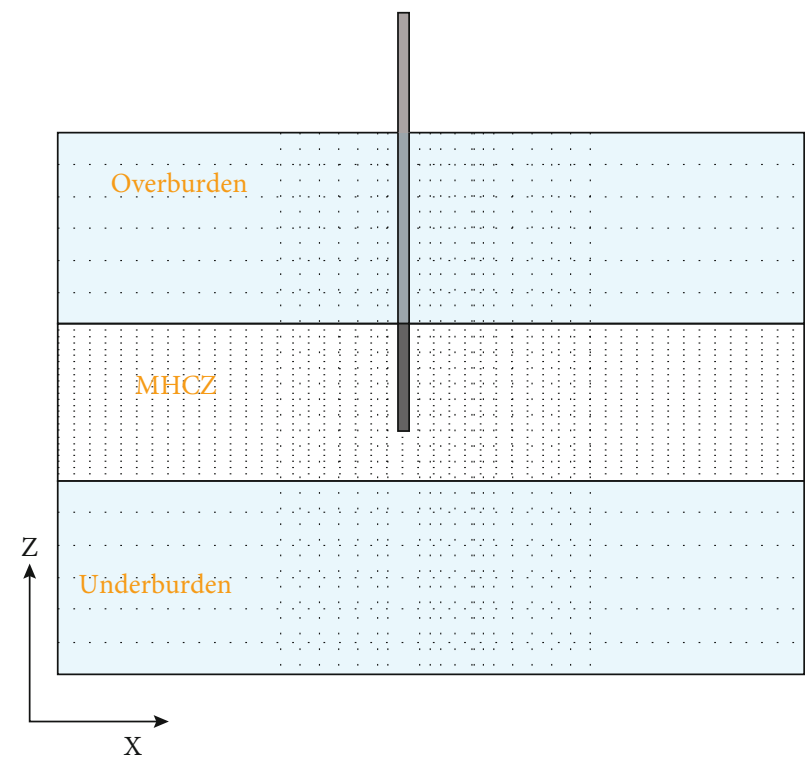

FIgURE 5: The corresponding grids used in the simulations.

Depressurization result in the reservoir compression has effects on decreases in formation porosity and intrinsic permeability which account for the fluid flow behavior so the water production rate decreased after $t=15 \mathrm{~d}$. The average values of gas production rate are about $3080 \mathrm{~m}^{3} / \mathrm{d}$.

3.2. Evolution of Physical Properties. Figure 8 indicates the evolution of pressure, temperature, hydrate saturation, and gas saturation in the hydrate reservoir due to depressurization within a one-year production. Physical properties are significant for analyzing the decomposition behavior of hydrates.

3.2.1. Spatial Distribution of Pressure. Figure 8(a) shows the spatial distribution of pressure in the hydrate reservoir due to depressurization. The production well is located in the center of the model. In the early stage, pressure in the well- bore reduced rapidly which create a high-pressure gradient near the production well. Then, the pressure gradient extends along $\mathrm{X}$ and $\mathrm{Y}$ directions. With hydrate dissociating, the effective permeability increased so the pressure conducted faster in the dissociation region. The range of depressurization is over $150 \mathrm{~m}$ during a one-year exploitation.

3.2.2. Spatial Distribution of Temperature. In Figure 8(b), the spatial distribution of temperature of the hydrate reservoir is shown. Decomposition of hydrate is an endothermic process which means the low-temperature zone is connected with the hydrate decomposition. The low-temperature zone extends more rapidly in MHCZ with high hydrate saturation and high permeability. The range of the temperature reduction zone is over $150 \mathrm{~m}$ during a one-year exploitation as well. 
TABLE 1: Hydrate deposit properties at the NGHP-02-16 site.

\begin{tabular}{|c|c|c|c|}
\hline Parameter & Value & Parameter & Value \\
\hline Water depth [38] & $2546.5 \mathrm{~m}$ & Dry thermal conductivity & $1.0 \mathrm{~W} \mathrm{~m}^{-1{ }^{\circ}} \mathrm{C}^{-1}$ \\
\hline Overburden thickness & $30 \mathrm{~m}$ & Wet thermal conductivity & $2.917 \mathrm{~W} \mathrm{~m}^{-1{ }^{\circ}} \mathrm{C}^{-1}$ \\
\hline Underburden thickness & $30 \mathrm{~m}$ & Geothermal gradient [35] & $0.066^{\circ} \mathrm{C} / \mathrm{m}$ \\
\hline MHCZ thickness & $24 \mathrm{~m}$ & Pressure at the bottom of the MHCZ & $28.79 \mathrm{MPa}$ \\
\hline Gas composition & $100 \% \mathrm{CH}_{4}$ & Rock grain density & $2600 \mathrm{~kg} / \mathrm{m}^{3}$ \\
\hline Water salinity & $3.5 \%$ & Seafloor temperature & $1.98^{\circ} \mathrm{C}$ \\
\hline Porosity of MHCZ [38-40] & 0.40 & Hydrate saturation in $\mathrm{MHCZ}[33,35,38]$ & 0.7 \\
\hline Diameter of lateral branch & $40 \mathrm{~mm}$ & Diameter of main borehole & $0.1 \mathrm{~m}$ \\
\hline Intrinsic permeability of MHCZ & $\begin{array}{c}k_{x}=k_{y}=100 \mathrm{mD} \\
k_{z}=50 \mathrm{mD}\end{array}$ & Pore compressibility & $1.0 \times 10^{-8} \mathrm{~Pa}^{-1}$ \\
\hline Capillary pressure model [43] & \multicolumn{3}{|c|}{$P_{\text {cap }}=-P_{0}\left[\left(S^{*}\right)^{-1 / \mathrm{m}}-1\right]^{1-\mathrm{m}} S^{*}=\left(S_{A}-S_{\mathrm{irA}}\right) /\left(S_{\mathrm{mxA}}-S_{\mathrm{irA}}\right)$} \\
\hline$S_{\mathrm{mxA}}[36]$ & 1.0 & $P_{0}[45]$ & $1.0 \times 10^{5} \mathrm{~Pa}$ \\
\hline$m$ & 0.45 & $\mathrm{~S}_{\mathrm{irA}}$ & 0.39 (clay), 0.29 (sand) \\
\hline Relative permeability model [44] & \multicolumn{3}{|c|}{$K_{\mathrm{rA}}=\left[\left(S_{A}-S_{\mathrm{irA}}\right) /\left(1-S_{\mathrm{irA}}\right)\right]^{n} K_{\mathrm{rG}}=\left[\left(S_{G}-S_{\mathrm{irG}}\right) /\left(1-S_{\mathrm{irA}}\right)\right]^{\mathrm{nG}}$} \\
\hline$n[44]$ & 5.0 & $n_{G}[46]$ & 3.572 \\
\hline$S_{\mathrm{irA}}$ & 0.40 (clay), 0.29 (sand) & $S_{\text {irG }}$ & 0.05 \\
\hline
\end{tabular}

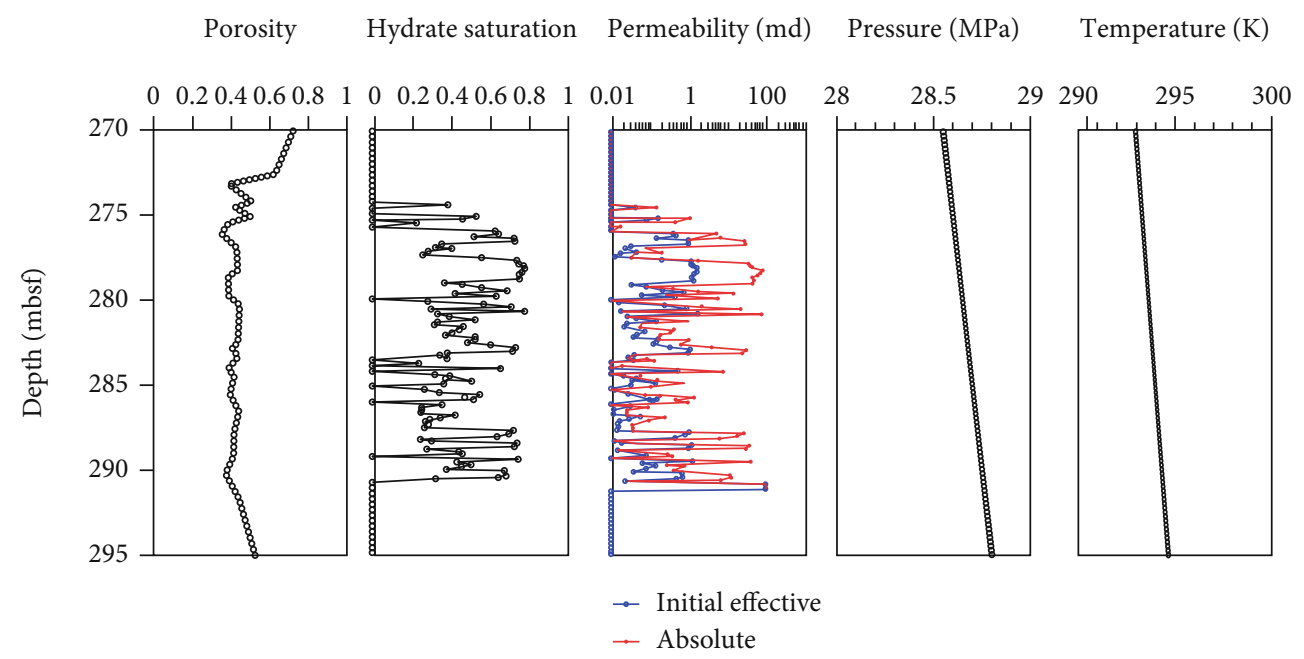

FiguRE 6: Left to right: Depth profiles of effective porosity, hydrate saturation, initial effective and absolute permeabilities, pressure, and temperature around the MHCZ at site NGHP-02-16 [38].

3.2.3. Spatial Distribution of Hydrate Saturation. Figure 8(c) indicates the spatial distribution of hydrate saturation in the hydrate reservoir due to depressurization. The spatial distribution of hydrate saturation could directly reveal the dissociation performance. The hydrate dissociates mainly around the production well and dissociates a lot in $\mathrm{X}$ and $\mathrm{Y}$ directions. That may be hydrate dissociation increases the effective permeability of the deposits anisotropic permeability makes the pressure decrease rapidly in these two directions. During a 365-day production, hydrate has completely dissociated within approximately 40 meters around the well.
3.2.4. Spatial Distribution of Gas Saturation. The spatial distribution of gas hydrate plays an important role in understanding the gas production behaviors and to evaluate the formation of "secondary hydrate." In Figure 8(d), we could see that the occurrence area of free gas has increased with its saturation decreased. The "secondary hydrate" can be observed in the zone about $50 \mathrm{~m}$ away from the production well. This saturation occurs mainly for the reason that as hydrate decomposed, this area forms a low-temperature zone. However, the pressure distribution gradually tends to be stable. The free gas and water reforming hydrate in the zone with low temperature and high pressure. 


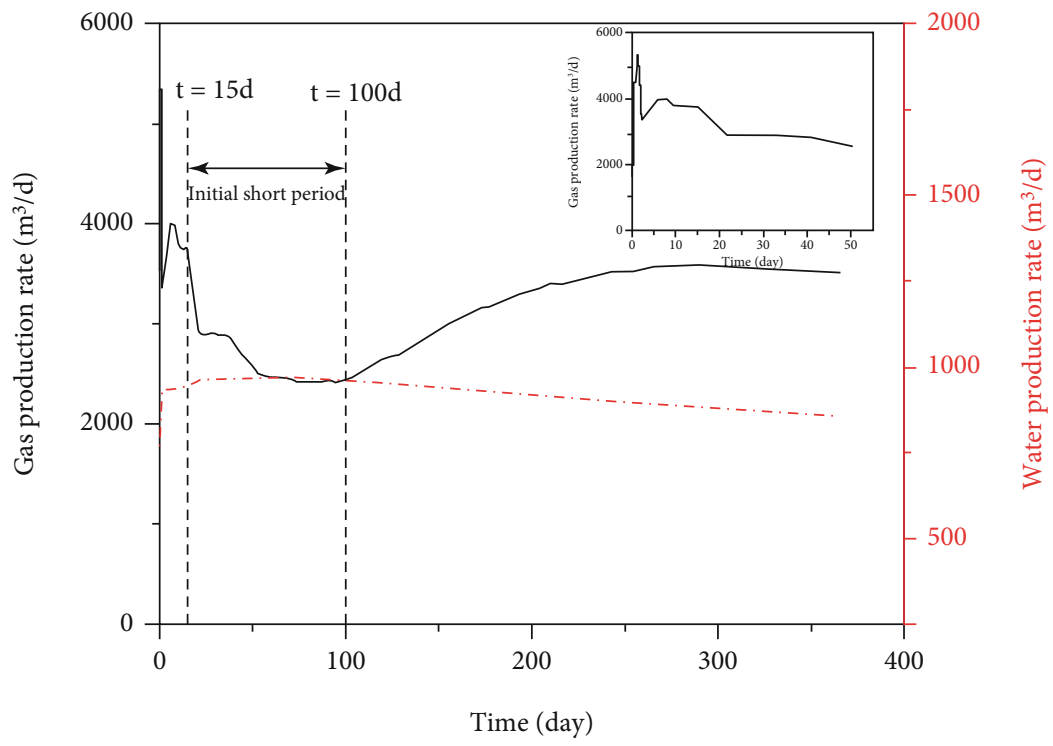

Figure 7: Volumetric rates of the gas production and water production in the well recovered from hydrate reservoir within 365 days at NGHP-02-16 site. The inset shows volumetric rates of the gas production from hydrate reservoir within 50 days.

\section{Discussion}

The single vertical well has its limitation on gas hydrate exploitation. For example, the limited contact area of a single vertical well will limit the transfer range of temperature and pressure during the exploitation which will affect the hydrate decomposes rate. Consequently, the well structure and production strategy needs to be optimized for improving the gas recovery efficiency. According to previous research, the optimal combination of geometric parameters and distribution manner of multilateral branches is vital for improving the gas recovery of multilateral well [42]. There are two distribution manners of multilateral branches based on the span scale of multilateral branches. Type A is the well profile with a vertical depth of multilateral branch that outweighs the reservoir depth, and the well profile named type B is a vertical depth of multilateral branch that is less than the hydrate reservoir thickness. Type A profile has the advantage of long-term stimulation but higher drilling and completion difficulties. Type B profile can quickly stimulate the hydrate decomposed but instability of geotechnical engineering may put the reservoir at risk [27]. Therefore, we take Type A profile to simulate the gas production performance by multilateral well under depressurization (Figure 9).

This paper mainly deals with the impact of geometric parameters (dip angle of lateral branch, number of lateral branches, and spacing of lateral branches) on multilateral well productivity. All of the multilateral vertical well models are based on the single vertical well model mentioned above.

4.1. Different Dip Angle of Lateral Branch. Three different cases (Figure 10) with different dip angles (dip angle $=30^{\circ}$, $45^{\circ}$, and $60^{\circ}$ ) of the lateral branch (Table 2) are designed to investigate the effects of the dip angle of the lateral branch on gas production performance of two branches well. The bottom hole pressure is maintained at $19 \mathrm{MPa}$, and the other physical properties of the hydrate reservoir are the same. The lateral branches are distributed symmetrically on the two sides of the main wellbore. Figure 11 shows the evolution of the volumetric rate $\left(Q_{G}\right)$ of produced gas at multilateral vertical well and the evolution of volumetric rates of water production $\left(Q_{W}\right)$. In Figure 11(a), we could see that the volumetric rate of gas production in Case 1-3 is significantly higher than that in Case 1-1 and Case 1-2. The average values of $Q_{G}$ in Case 1-1, Case 1-2, and Case 1-3 are about 3580, 3944 , and $4891 \mathrm{~m}^{3} / \mathrm{d}$. According to Figure 11(b), the volumetric rate of water production $Q_{W}$ in Case1-3 is the highest. The average values of $Q_{W}$ in Case 1-1, Case 1-2, and Case 1-3 are about 1118,1224 , and $1425 \mathrm{~m}^{3} / \mathrm{d}$. Figure 12 shows the evolution of gas-to-water ratio $\left(R_{\mathrm{GW}}\right)$ for one-year production period. Initially, the $R_{\mathrm{GW}}$ of multilateral wells is slightly lower than that of single vertical well. After 50 days' production, the $R_{\mathrm{GW}}$ of multilateral wells obviously higher than the $R_{\mathrm{GW}}$ of single vertical well and the $R_{\mathrm{GW}}$ in Case 1-3 is the highest. During the late stages of the production, the $R_{\mathrm{GW}}$ in Case 1-2 and Case 1-3 declined rapidly. This can also be verified by the corresponding hydrate and gas saturation distributions (Figure 13). During the 365-day production, the hydrate decomposed faster and extending a wider range in Case 1-3 compared with the others. In Figure 13(f), $25 \mathrm{~m}$ around the lateral branch exists the "second hydrate."

Both the absolute criteria and relative criteria discussed earlier illustrate the obvious superiority of Case 1-3 and Case 1-2. This may be because the larger dip angle of the lateral branch means the longer vertical depth of the lateral branch. So, the contact area of the multilateral well is extended which is beneficial for pressure and temperature to transmit. However, more hydrate decomposed comes with the higher water production even produced the "second hydrate" which have an impact on hydrate long-term exploitation. Consequently, 


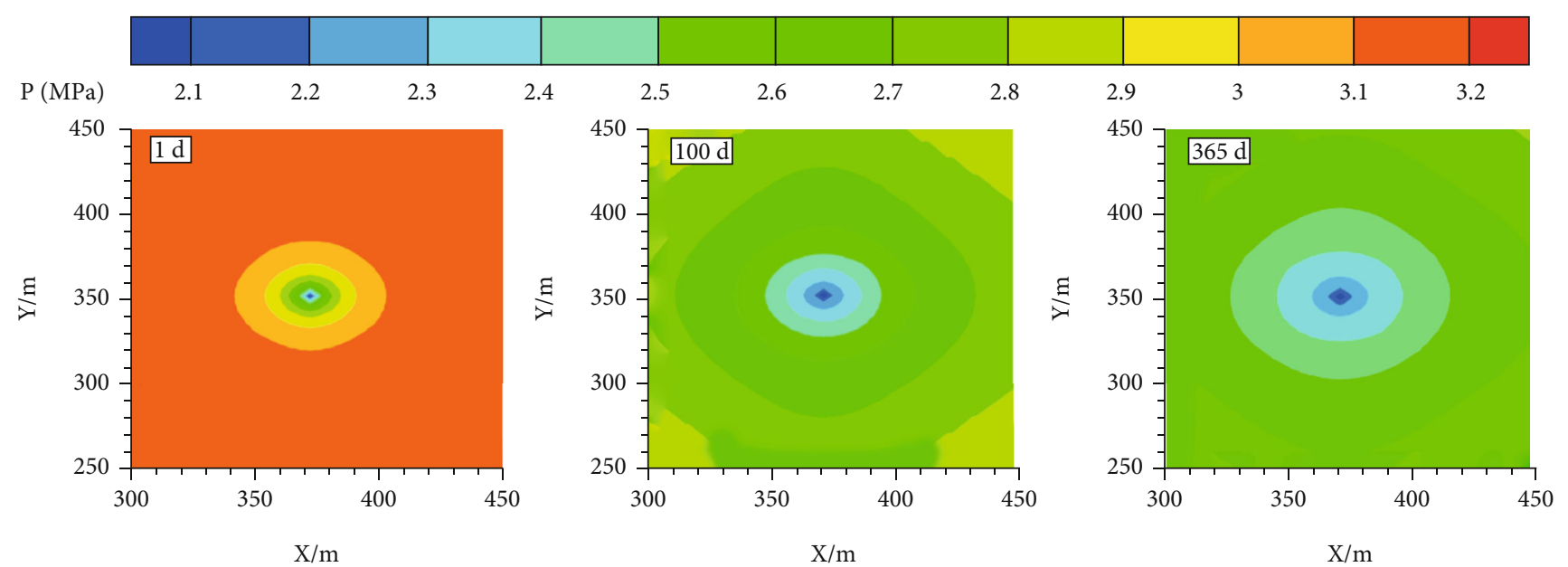

(a) Pressure
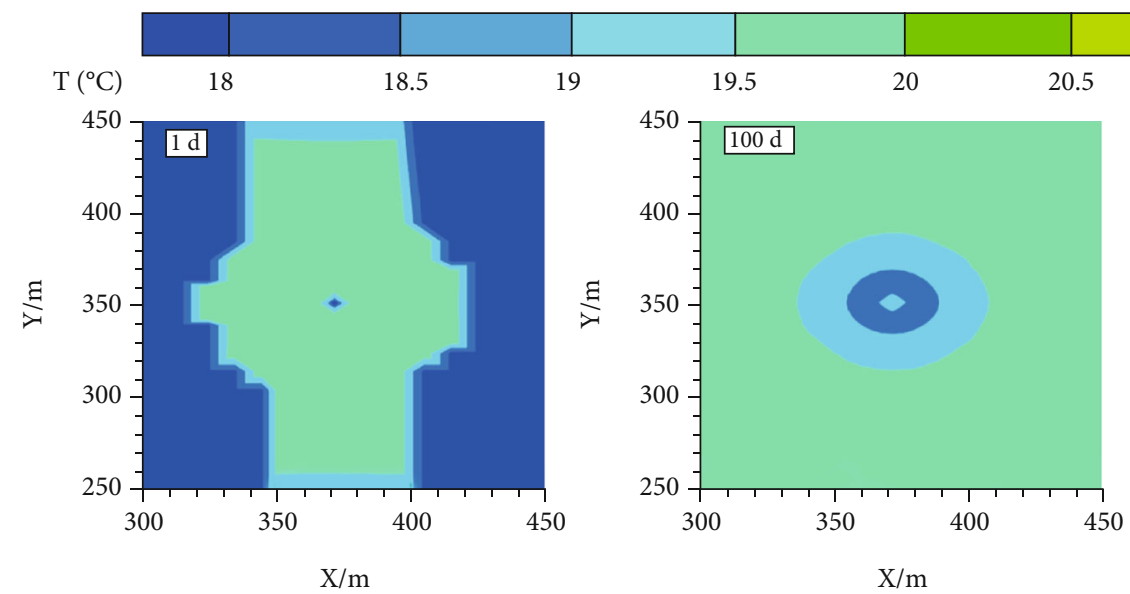

(b) Temperature
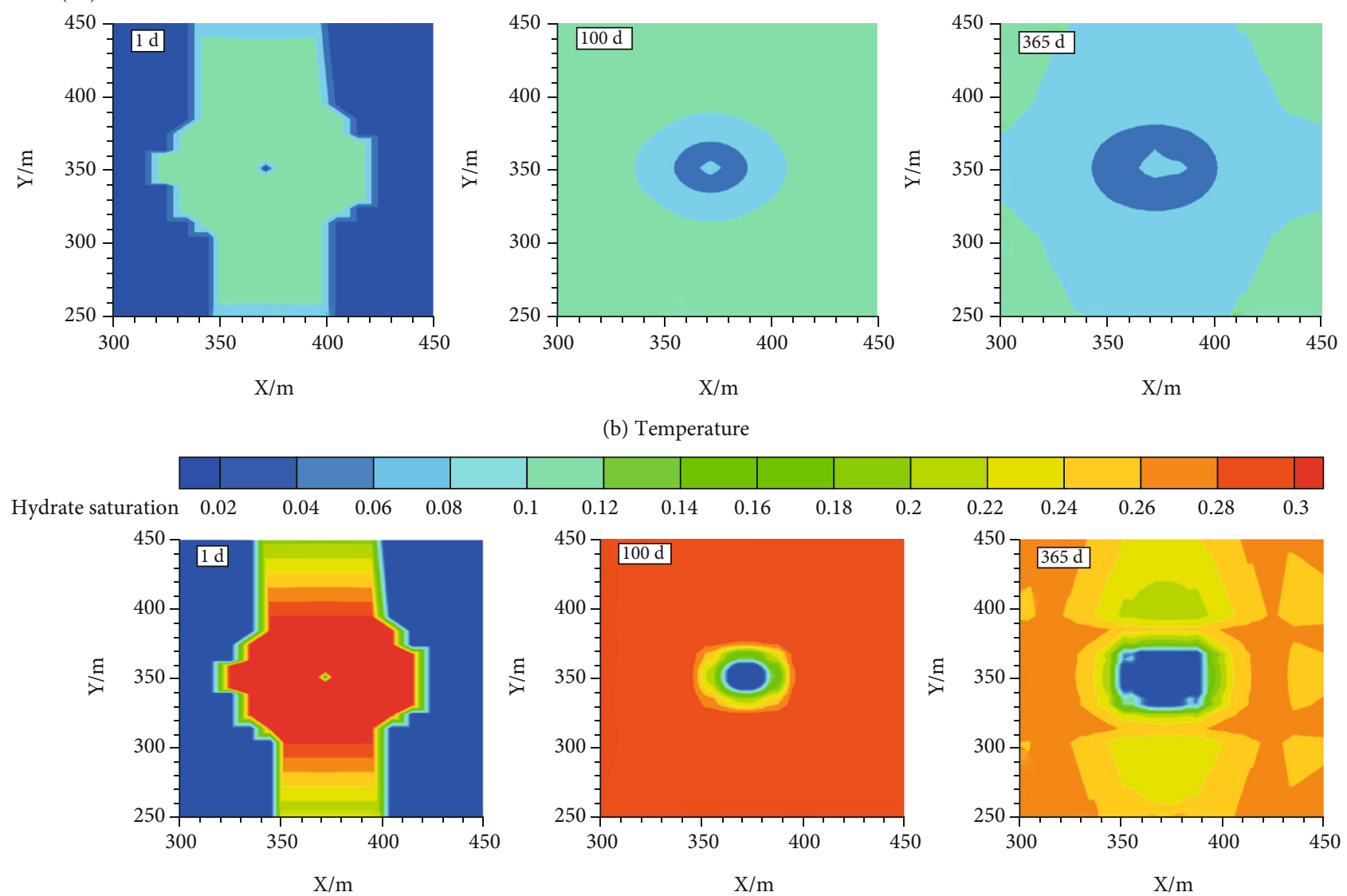

(c) Hydrate saturation

Figure 8: Continued. 


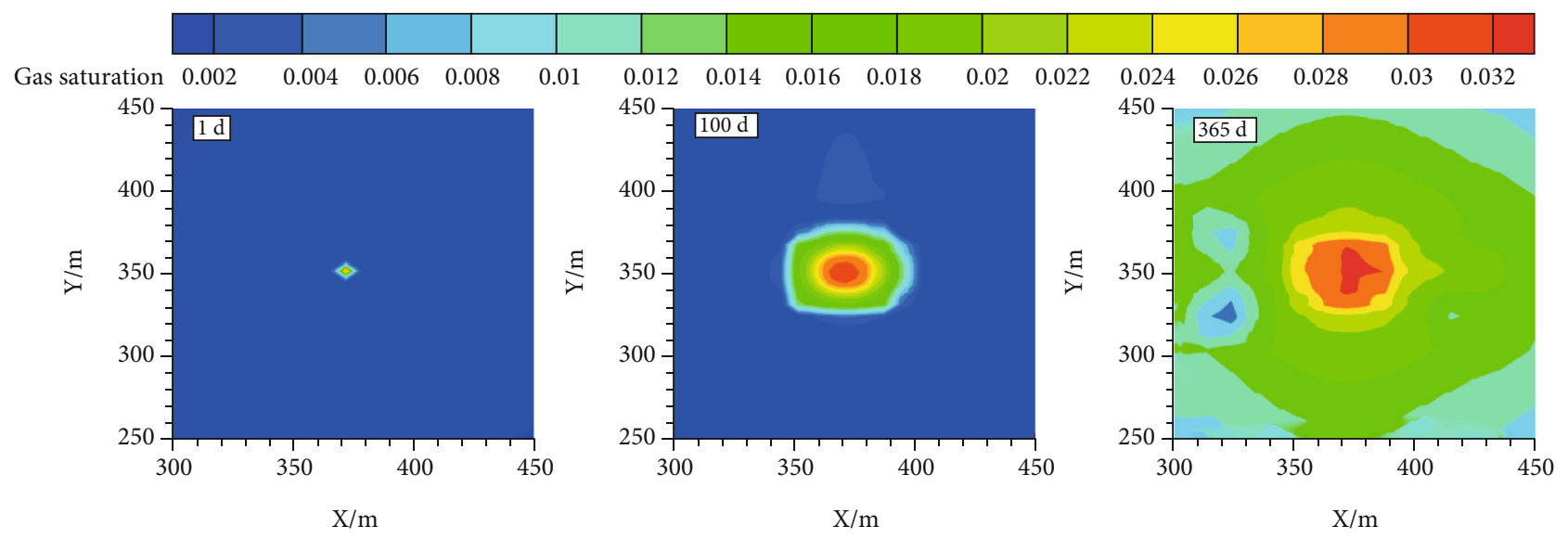

(d) Gas saturation

FIGURE 8: Evolution of physical properties in the simulated hydrate deposits.

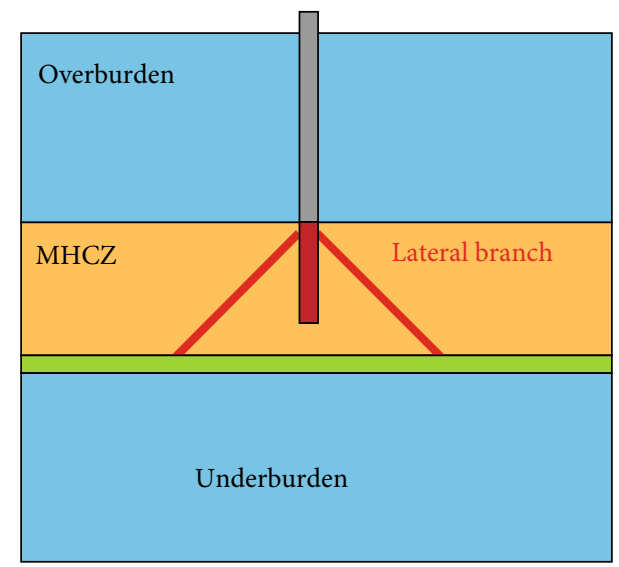

(a) Type A

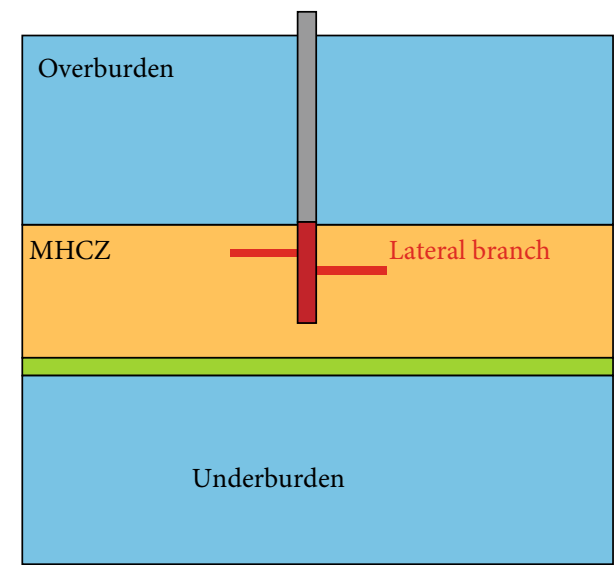

(b) Type B

Figure 9: Different distribution manners of multilateral branches [25].

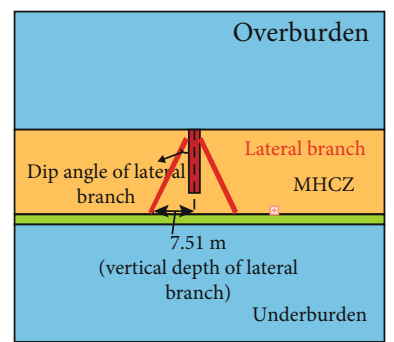

Case 1-1

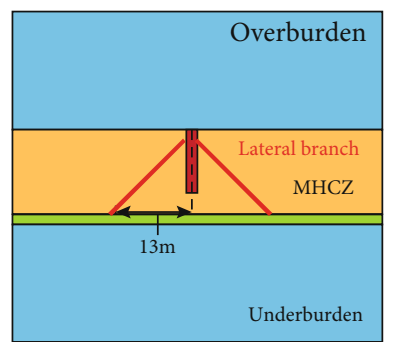

Case 1-2

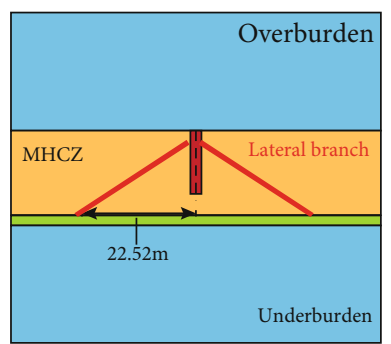

Case 1-3

Figure 10: Different dip angles (dip angle in Case 1-1, Case 1-2, and Case 1-3 are $30^{\circ}, 45^{\circ}$, and $60^{\circ}$ ) of the lateral branch (in $\mathrm{X}$ and $\mathrm{Z}$ directions).

we used Case 1-2 which the dip angle of the lateral branch is $45^{\circ}$ to study the optimal combination of the other geometric parameters.
4.2. Different Numbers of Lateral Branches. Three different cases with different numbers of the lateral branch (number of lateral branches are 2,3, and 4) of the lateral branch 
TABLE 2: Different dip angles of lateral branch designs are investigated in the simulations.

\begin{tabular}{|c|c|c|c|c|c|}
\hline Case & $\begin{array}{c}\text { Lateral branches } \\
\text { spacing/m }\end{array}$ & $\begin{array}{l}\text { Dip angle of } \\
\text { lateral branch }\end{array}$ & $\begin{array}{l}\text { Phase angle of } \\
\text { lateral branches }\end{array}$ & $\begin{array}{l}\text { Vertical depth of } \\
\text { lateral branch } / \mathrm{m}\end{array}$ & $\begin{array}{c}\text { Diameter of } \\
\text { lateral branch } / \mathrm{mm}\end{array}$ \\
\hline $1-1$ & 0 & $30^{\circ}$ & $180^{\circ}$ & 7.51 & 80 \\
\hline $1-2$ & 0 & $45^{\circ}$ & $180^{\circ}$ & 13 & 80 \\
\hline $1-3$ & 0 & $60^{\circ}$ & $180^{\circ}$ & 22.52 & 80 \\
\hline
\end{tabular}

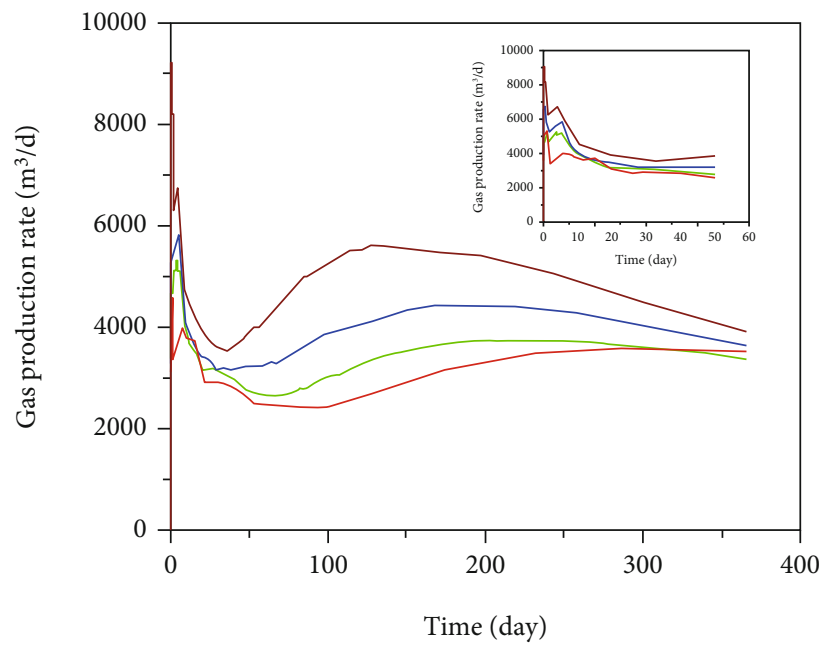

(a)

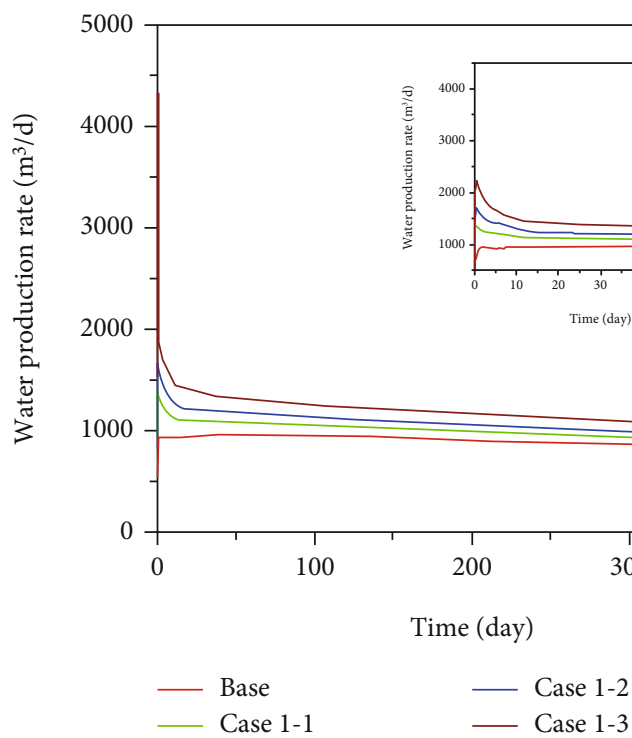

(b)

FIGURE 11: Evolution of volumetric rates of (a) gas production rate and (b) water production rate from hydrate reservoirs under different dip angles of the lateral branch during the one-year production period. The inset shows volumetric rates of the gas production and water production from hydrate reservoir within 50 days.

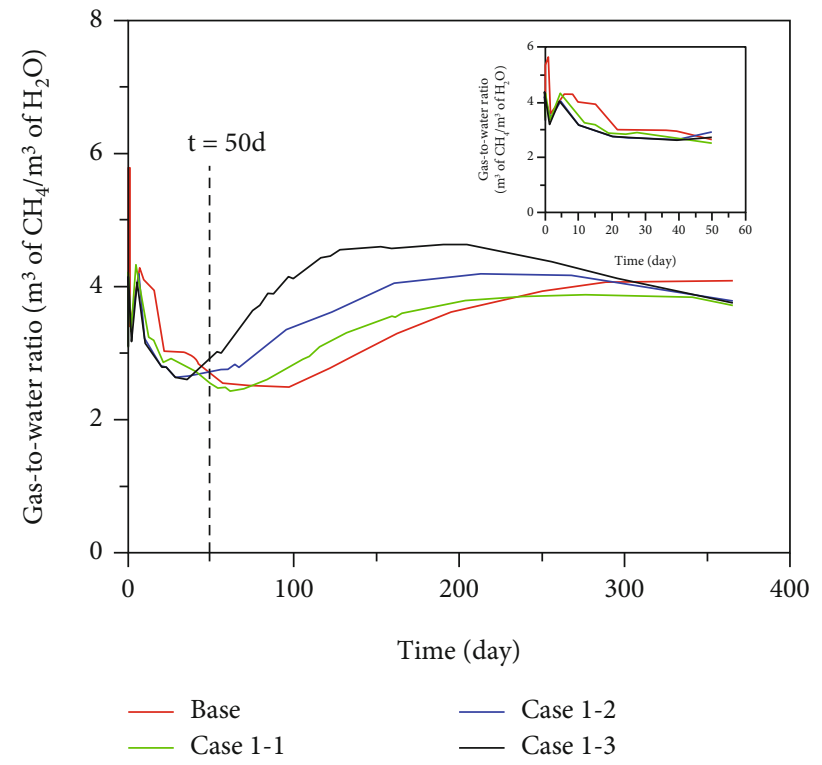

FIGURE 12: Evolution of gas-to-water ratio $\left(R_{\mathrm{GW}}\right)$ under different dip angles of lateral branch during the one-year production period. The inset shows evolution of gas-to-water ratio during 50 -day production. 


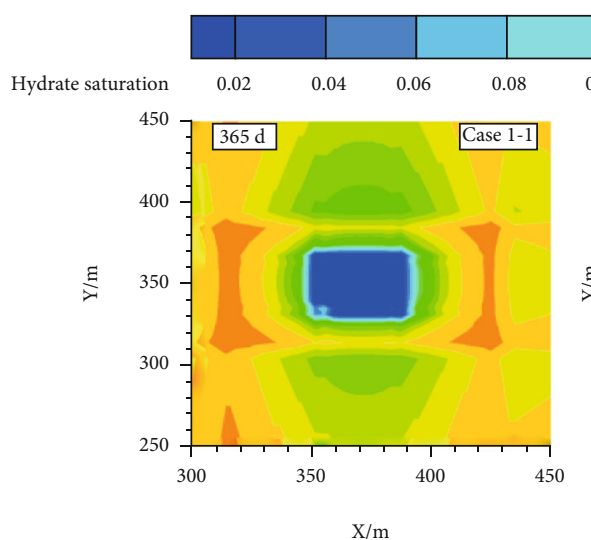

(a)

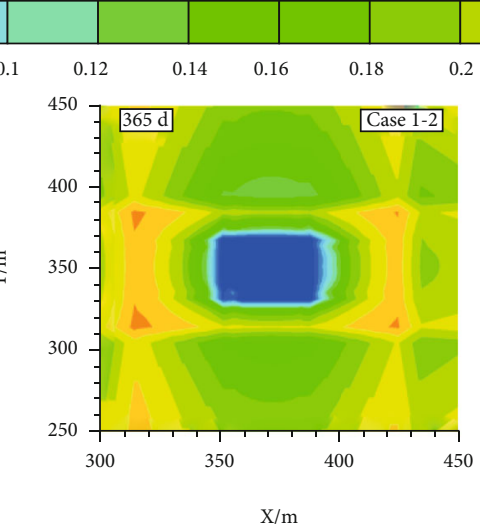

(b)
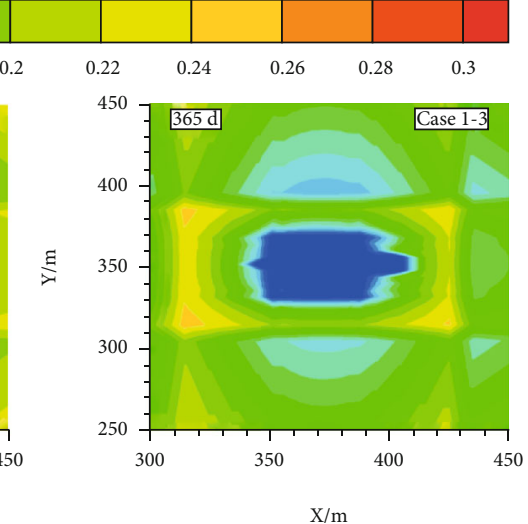

(c)

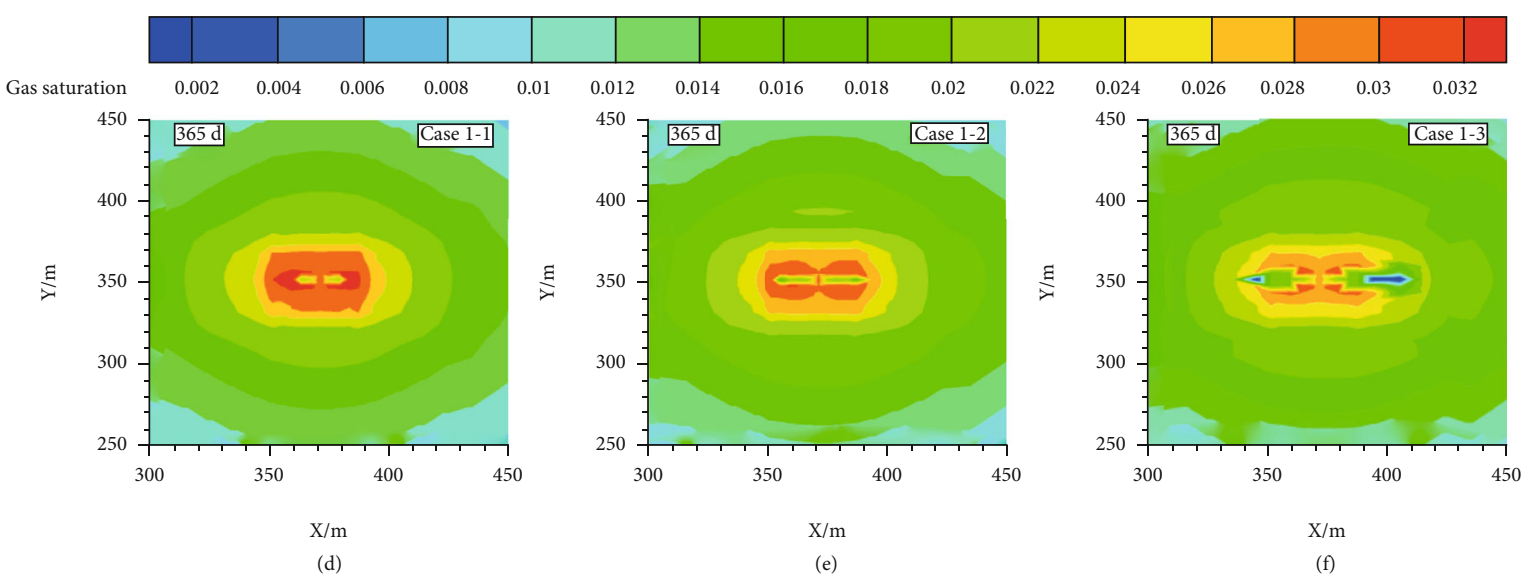

FIGURE 13: The distributions of hydrate saturation and gas saturation under conditions of different dip angles of the lateral branch at $t=365$ days.

TABLE 3: Different numbers of lateral branch designs are investigated in the simulations.

\begin{tabular}{ccccccc}
\hline Case & $\begin{array}{c}\text { Lateral branches } \\
\text { spacing/m }\end{array}$ & $\begin{array}{c}\text { Dip angle of } \\
\text { lateral branch }\end{array}$ & $\begin{array}{c}\text { Phase angle of adjacent } \\
\text { lateral branches }\end{array}$ & $\begin{array}{c}\text { Vertical depth of } \\
\text { lateral branch/m }\end{array}$ & $\begin{array}{c}\text { Diameter of } \\
\text { lateral branch/mm }\end{array}$ & $\begin{array}{c}\text { Number of } \\
\text { lateral branches }\end{array}$ \\
\hline $2-1$ & 0 & $45^{\circ}$ & $180^{\circ}$ & 13 & 80 & 2 \\
$2-2$ & 0 & $45^{\circ}$ & $90^{\circ} / 180^{\circ}$ & 13 & 80 & 3 \\
$2-3$ & 0 & $45^{\circ}$ & $90^{\circ}$ & 13 & 80 & 4 \\
\hline
\end{tabular}

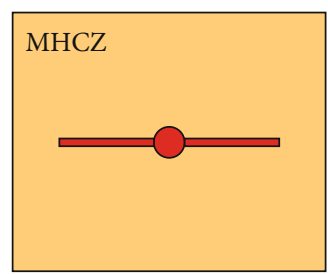

Case 2-1

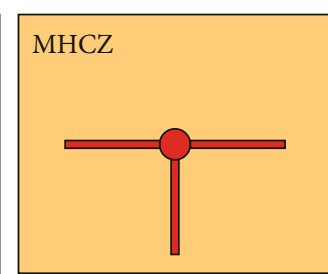

Case 2-2

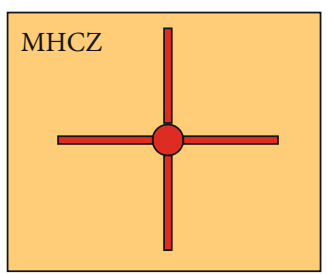

Case 2-3

FIGURE 14: Different numbers of the lateral branch (number of lateral branches in Case 2-1, Case 2-2, and Case 2-3 are 2, 3 , and 3) (in X and $\mathrm{Y}$ directions).

(Table 3) are investigated in this study to discuss the test production performance within one year. The distribution of lateral branches is shown in Figure 14. For comparison, the bottom hole pressure is maintained at $19 \mathrm{MPa}$, the dip angle of all lateral branches is $45^{\circ}$, and the other physical properties of the hydrate reservoir remain unchanged. In Figure 15(a), 


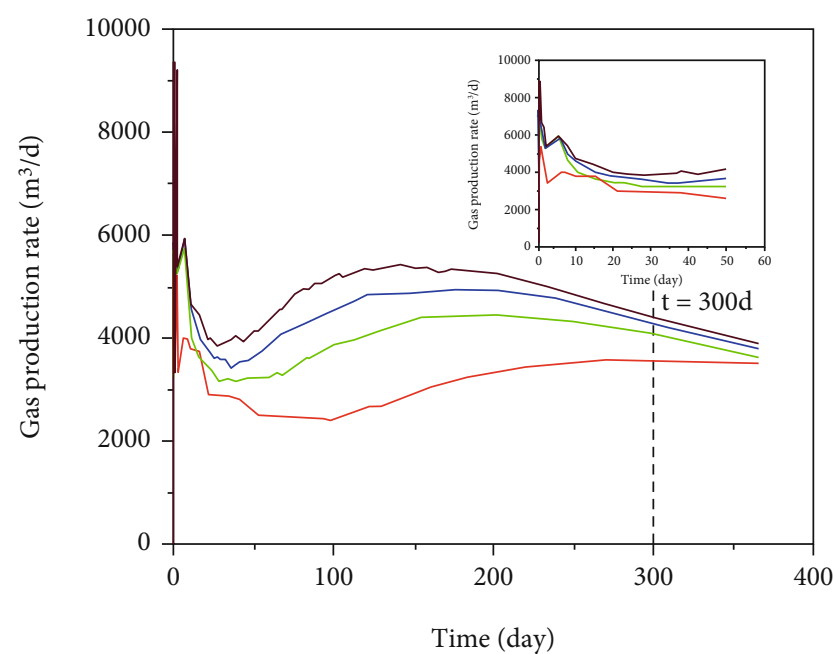

(a)

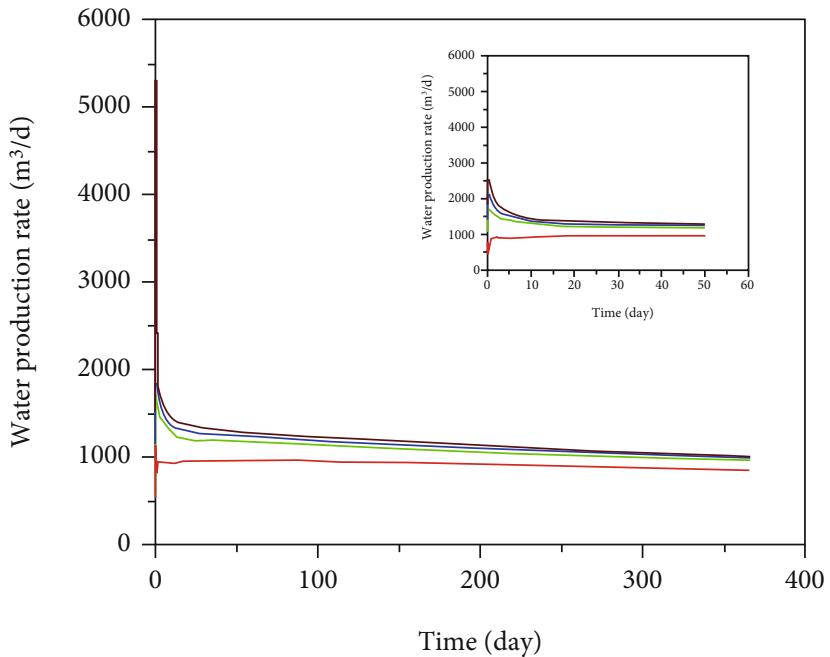

$\begin{array}{ll}\text { - Base } & \text { - Case 2-2 } \\ \text { Case 2-1 } & \text { Case 2-3 }\end{array}$

(b)

FIGURE 15: Evolution of volumetric rates of (a) gas production rate and (b) water production rate from hydrate reservoirs under different numbers of lateral branches during the one-year production period. The insert shows the gas production rate and water production rate during a 50-day production.

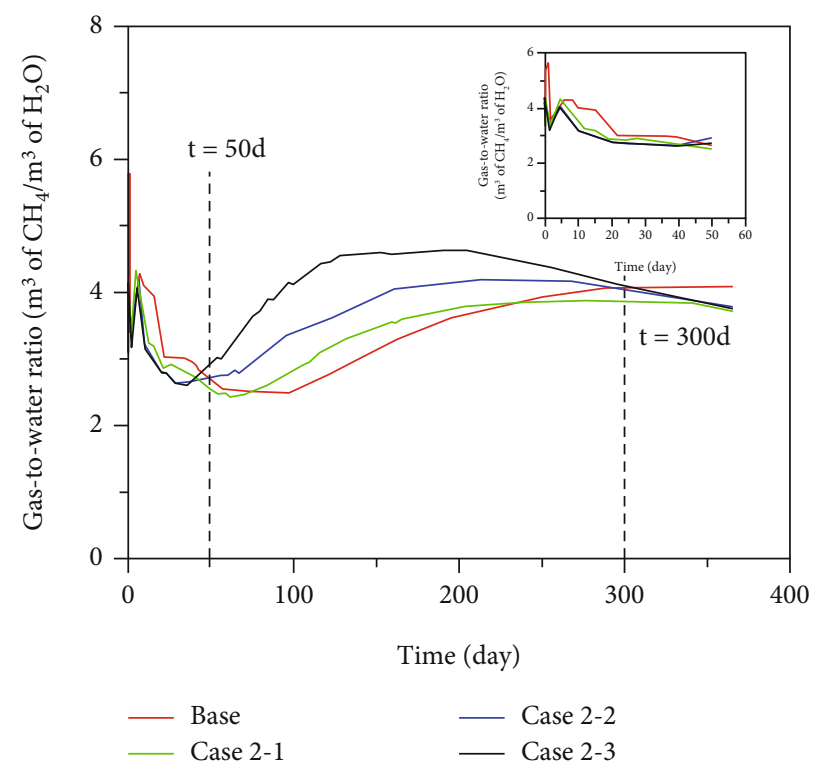

FIGURE 16: Evolution of gas-to-water ratio $\left(R_{\mathrm{GW}}\right)$ under different numbers of lateral branches during the one-year production period. The inset shows evolution of gas-to-water ratio during a 50 -day production.

$Q_{G}$ in Case 2-3 with the four lateral branches well is higher than the other cases. After $t=300 \mathrm{~d}, Q_{G}$ in Case $2-2$ is approaching to $Q_{G}$ in Case 2-3. The average values of $Q_{G}$ in Case 2-1, Case 2-2, and Case 2-3 are about 3944, 4386, and $4771 \mathrm{~m}^{3} / \mathrm{d}$. The difference of $Q_{W}$ in Case 2-1, Case 2-2, and Case 2-3 is very slight (Figure 15(b)). The average values of $Q_{W}$ in Case 2-1, Case 2-2, and Case 2-3 are about 1224, 1341 , and $1465 \mathrm{~m}^{3} / \mathrm{d}$. Figure 16 shows the evolution of $R_{\mathrm{GW}}$ during one-year production in different cases. Similarly, the $R_{\mathrm{GW}}$ of multilateral wells are slightly lower than that of single vertical well in initial time and the $R_{\mathrm{GW}}$ of multilateral wells dropped rapidly after 300 -day production. From $t=50 \mathrm{~d}$ to $t=300 \mathrm{~d}$, the $R_{\mathrm{GW}}$ in Case 2-3 higher than the $R_{\mathrm{GW}}$ in Case 2-2 and Case 2-1.

This can be explained by the characteristic of flow-related reservoir properties, as is shown in Figure 17. The pressure drops rapidly around the production interval causing significant hydrate decomposition and gas production. Increasing the branches of the multilateral wells causes the superposition of depressurization around the well which accelerates 


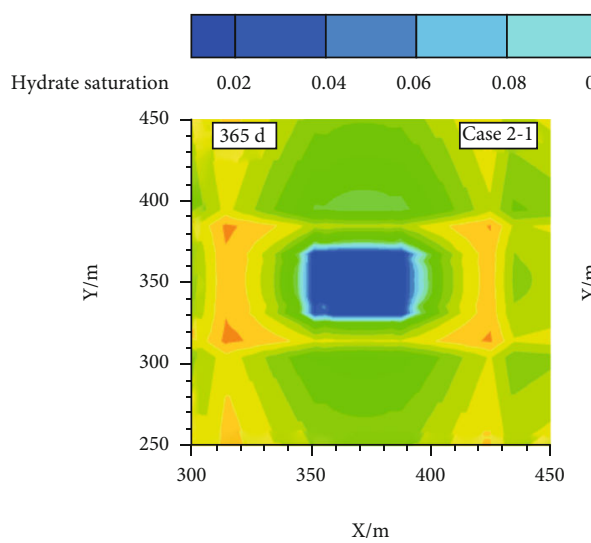

(a)

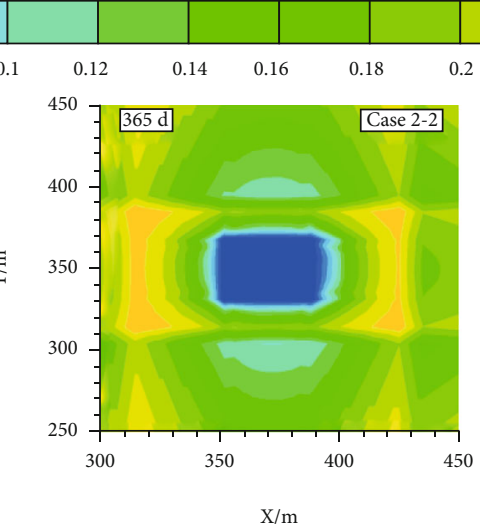

(b)
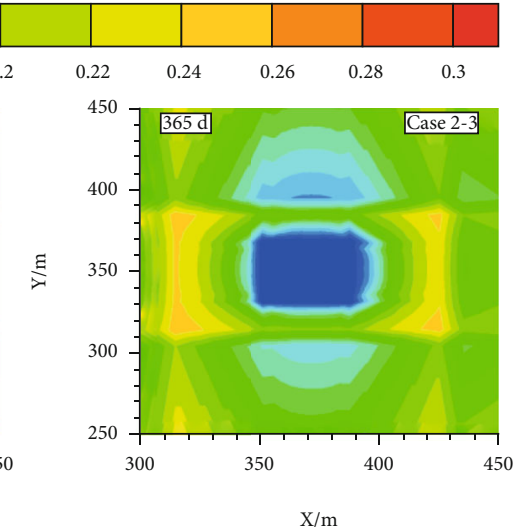

(c)

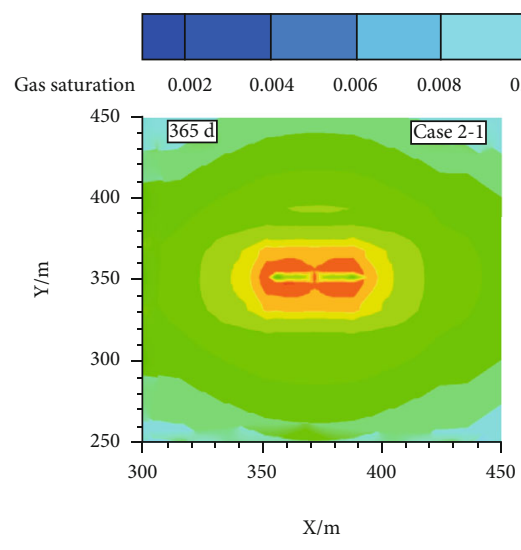

(d)

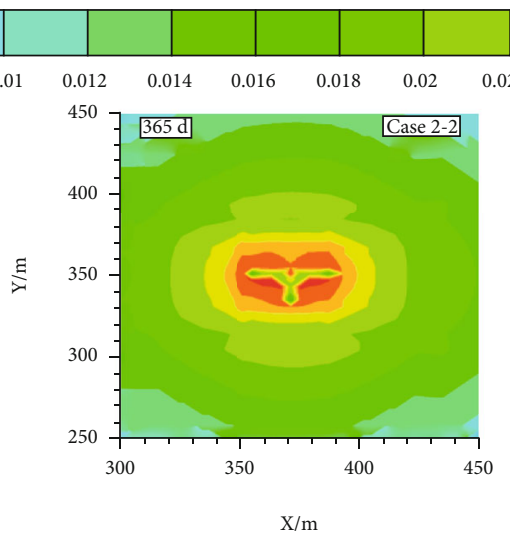

(e)
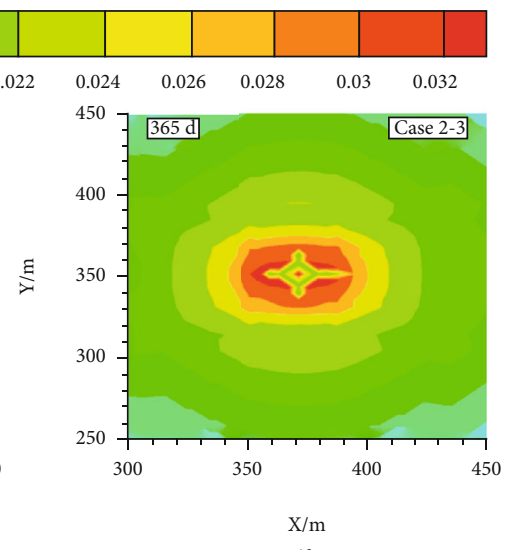

(f)

FIGURE 17: The distributions of hydrate saturation and gas saturation under conditions of different numbers of lateral branches at $t=365$ days.

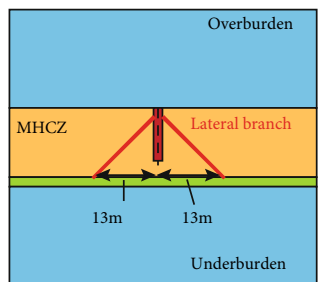

Case 3-1

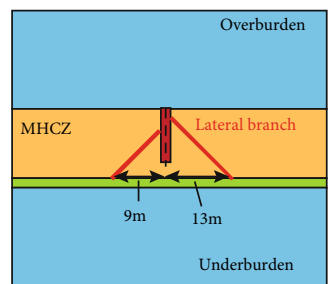

Case 3-2

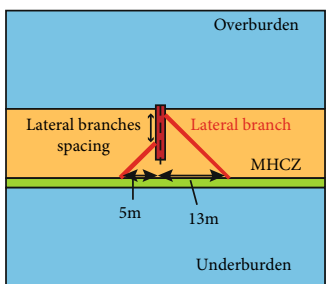

Case 3-3

Figure 18: Different spacing of lateral branches (spacing of lateral branches in Case 3-1, Case 3-2, and Case 3-3 are 0, 4, and $8 \mathrm{~m}$ ) (in X and $\mathrm{Z}$ directions).

TABLE 4: Different spacing of lateral branches designs is investigated in the simulations.

\begin{tabular}{ccccccc}
\hline Case & $\begin{array}{c}\text { Lateral branches } \\
\text { spacing/m }\end{array}$ & $\begin{array}{c}\text { Dip angle of } \\
\text { lateral branch }\end{array}$ & $\begin{array}{c}\text { Phase angle of adjacent } \\
\text { lateral branches }\end{array}$ & $\begin{array}{c}\text { Vertical depth of } \\
\text { lateral branch/m }\end{array}$ & $\begin{array}{c}\text { Diameter of } \\
\text { lateral branch/mm }\end{array}$ & $\begin{array}{c}\text { Number of } \\
\text { lateral branches }\end{array}$ \\
\hline $3-1$ & 0 & $45^{\circ}$ & $180^{\circ}$ & 13 & 80 & 2 \\
$3-2$ & 4 & $45^{\circ}$ & $180^{\circ}$ & $13 / 9$ & 80 & 2 \\
$3-3$ & 8 & $45^{\circ}$ & $180^{\circ}$ & $13 / 5$ & 80 & 2 \\
\hline
\end{tabular}

the decomposition of hydrate. However, interference of symmetrical flow field between branches will hinder gas-liquid flow, with a "static zone" occurred in the central of the branches. On the whole, compared with other cases, Case
2-3 has its advantages in a one-year production. The simulation results suggest that the favorable lateral branch number scheme should consider the well interference effect in the actual field test. 


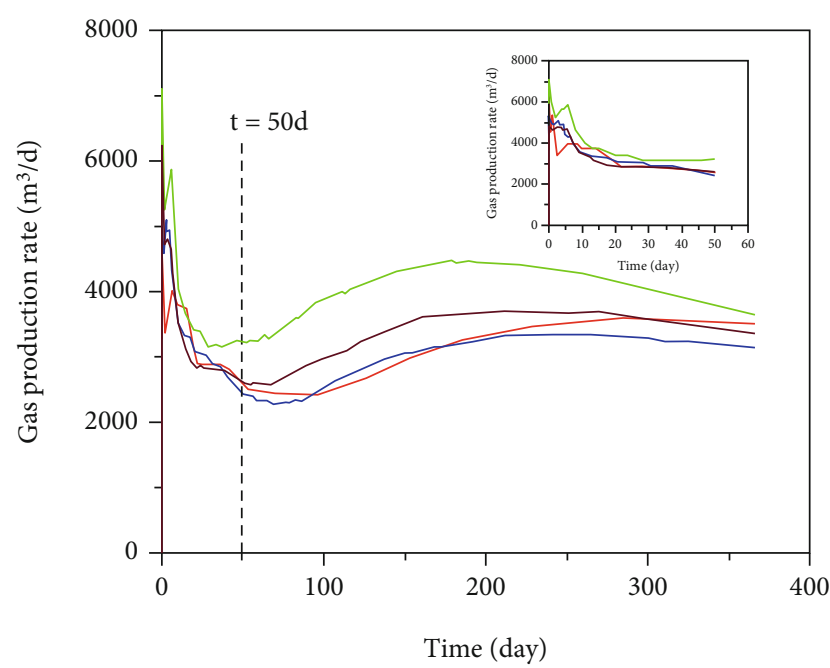

(a)

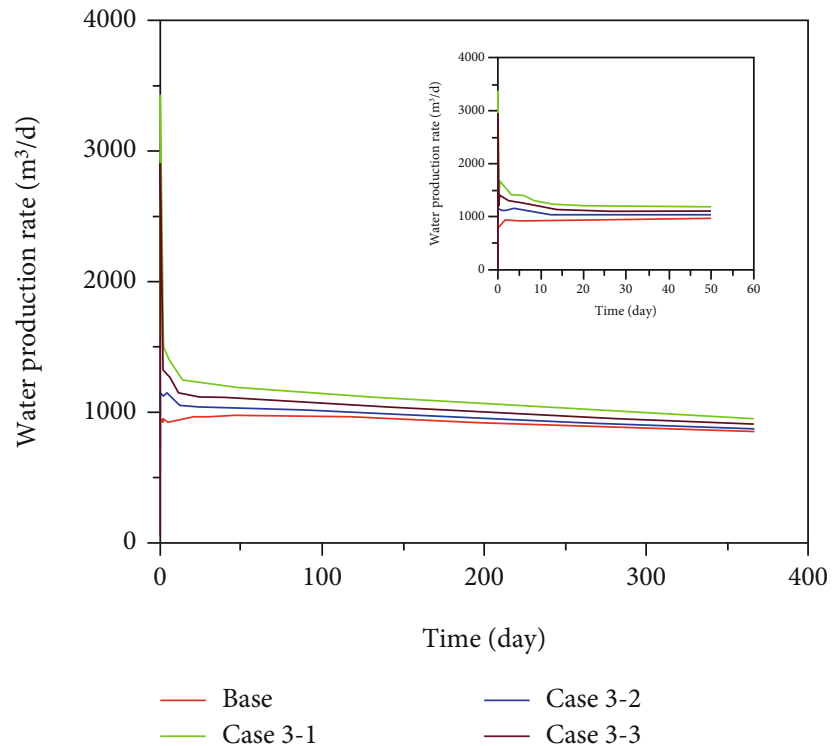

(b)

FIGURE 19: Evolution of volumetric rates of (a) gas production rate and (b) water production rate from hydrate reservoirs under different spacing of lateral branches during the one-year production period. The insert shows gas production rate and water production rate during a 50-day production.

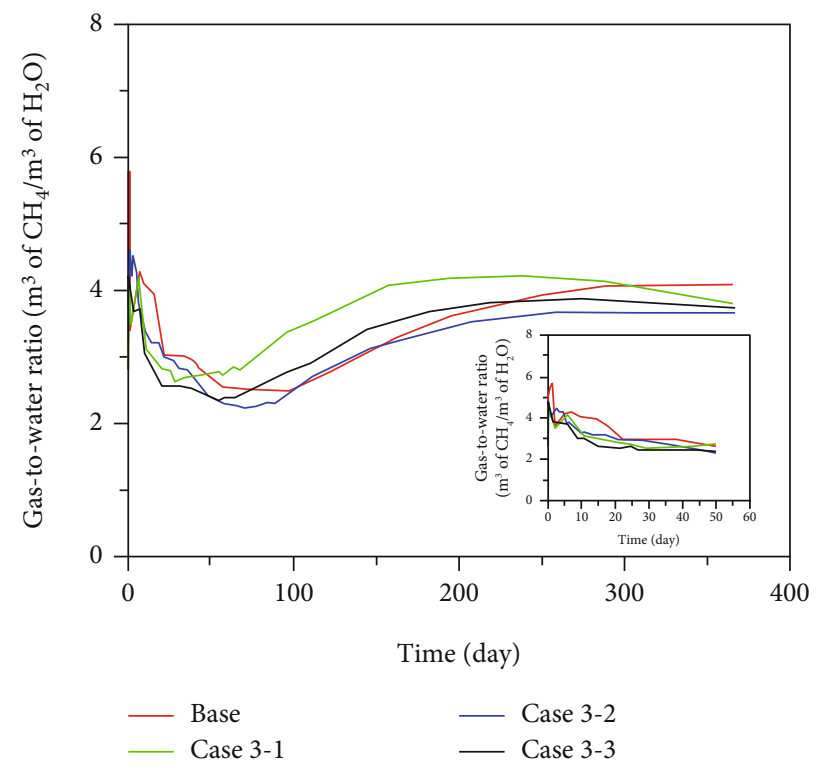

FIGURE 20: Evolution of gas-to-water ratio $\left(R_{\mathrm{GW}}\right)$ under different spacing of lateral branches during the one-year production period. The inset shows evolution of gas-to-water ratio during a 50 -day production.

4.3. Different Spacing of Lateral Branches. In this study, three different cases with different spacing of lateral branches (spacing of lateral branches are 0,4 , and $8 \mathrm{~m}$ ) (Figure 18, Table 4) are investigated to discuss the test production performance. For comparison, the bottom hole pressure is maintained at $19 \mathrm{MPa}$, the dip angle of all lateral branches is $45^{\circ}$, and the other physical properties of the hydrate reservoir remain unchanged. Figure 19 shows the evolution of the volumetric rate $\left(Q_{G}\right)$ of produced gas at multilateral vertical well and the evolution of volumetric rates of water production $\left(Q_{W}\right)$. As shown in Figure $19(\mathrm{a}), Q_{G}$ in Case 3-1 is the biggest in the three cases during the production. From $t=0 \mathrm{~d}$ to $t=50 \mathrm{~d}$ stage, $Q_{G}$ in Case $3-1$ is slightly higher than the other cases. The average values of $Q_{G}$ in Case 3-1, Case 3-2, and Case 3-3 are about 3944, 3134, and $3422 \mathrm{~m}^{3} / \mathrm{d}$. The difference of $Q_{W}$ in the three cases is very slight (Figure 19(b)). The average values of $Q_{W}$ in Case 3-1, Case 3-2, and Case 3-3 are about 1224,1014, and $1121 \mathrm{~m}^{3} / \mathrm{d}$. Figure 20 shows the evolution of gas-towater ratio $\left(R_{\mathrm{GW}}\right) . R_{\mathrm{GW}}$ in Case $3-1$ is higher than the 


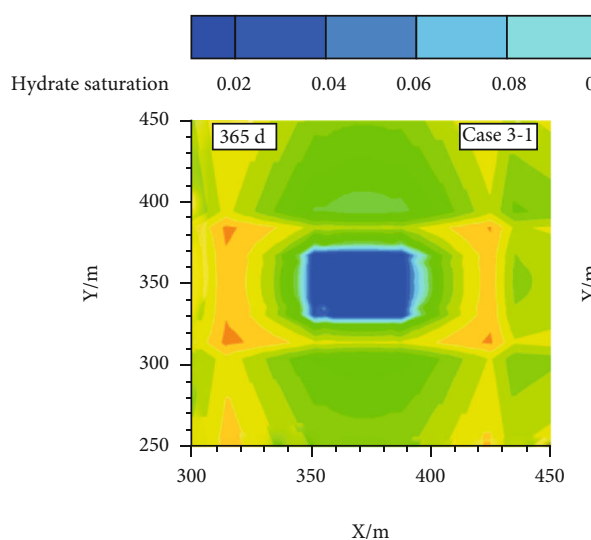

(a)

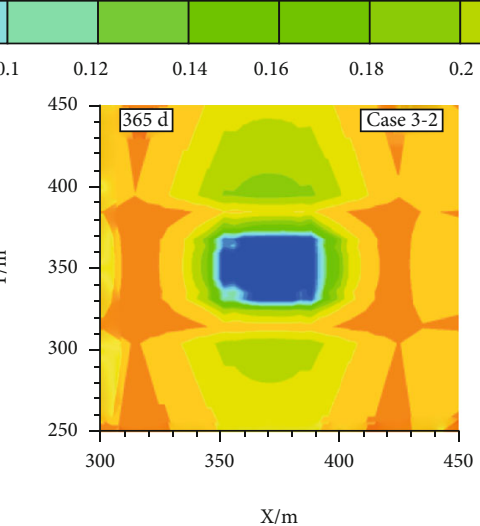

(b)
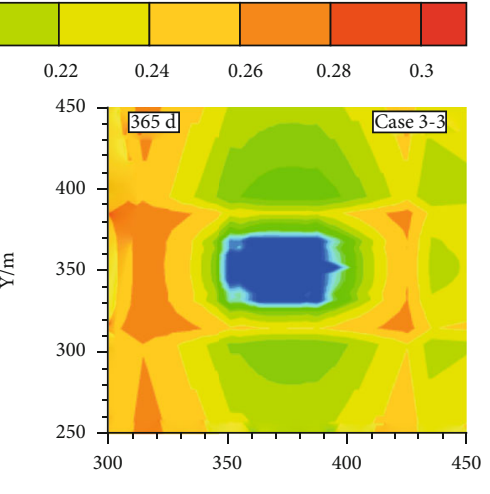

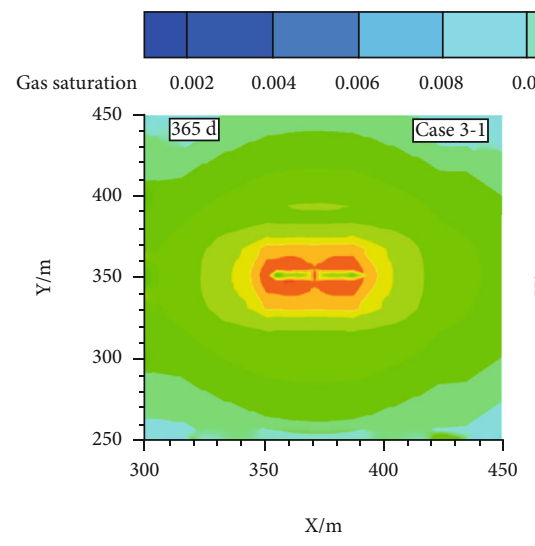

(d)

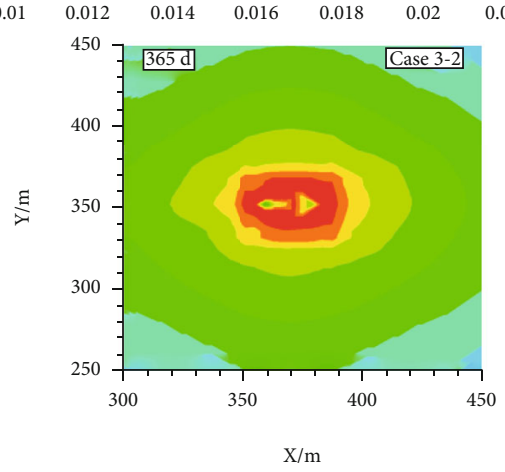

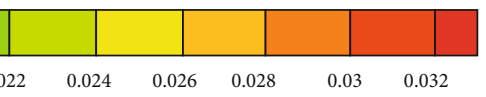

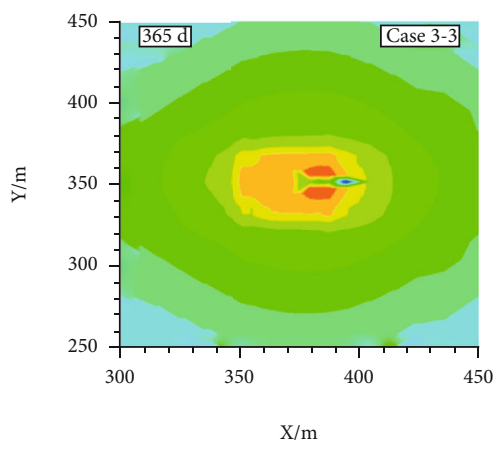

(f)

FIGURE 21: The distributions of hydrate saturation and gas saturation under conditions of different spacing of lateral branches at $t=365$ days.

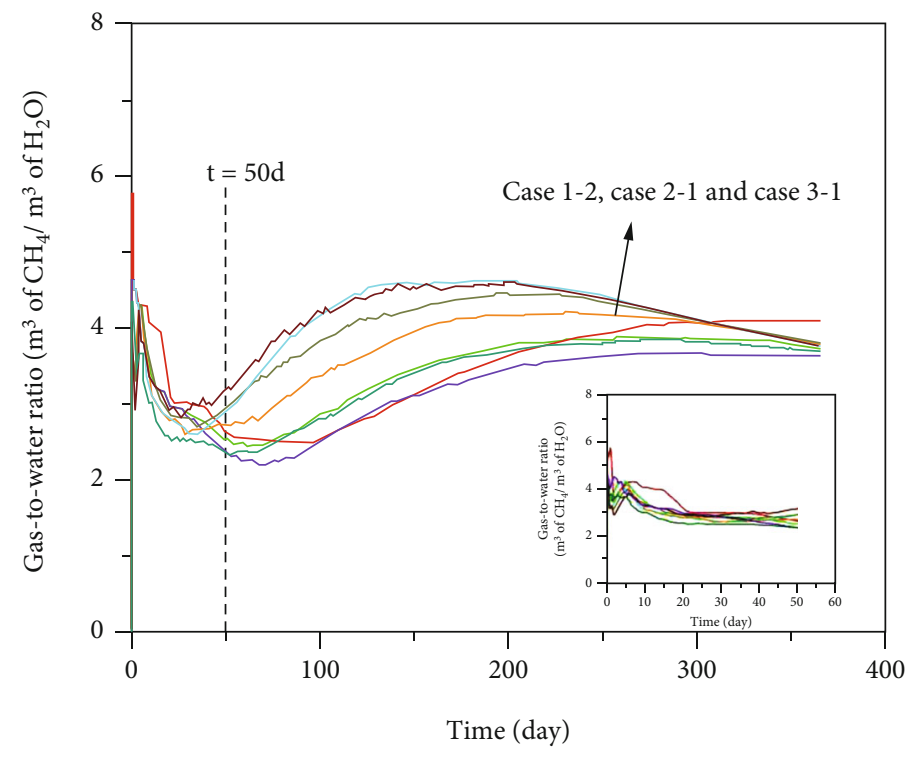

$\begin{array}{ll}\text { - Base } & \text { - Case 2-2 } \\ \text { Case 1-1 } & \text { Case 3-2 } \\ \text { Case 2-1 } & \text { Case 1-3 } \\ \text { Case 3-1 } & \text { Case 1-2 }\end{array}$

FIGURE 22: Evolution of gas-to-water ratio $\left(R_{\mathrm{GW}}\right)$ under different distributions of lateral branches during the one-year production period. The inset shows evolution of gas-to-water ratio during a 50 -day production. 


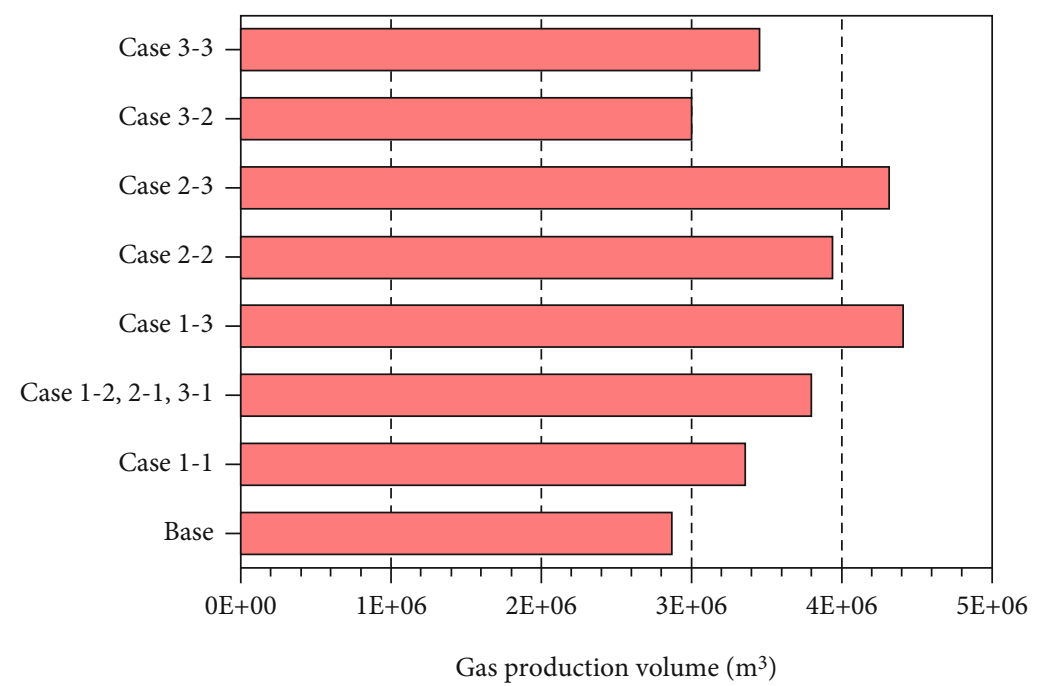

365 days

Figure 23: Gas production volumes under different distributions of lateral branches on 365 days.

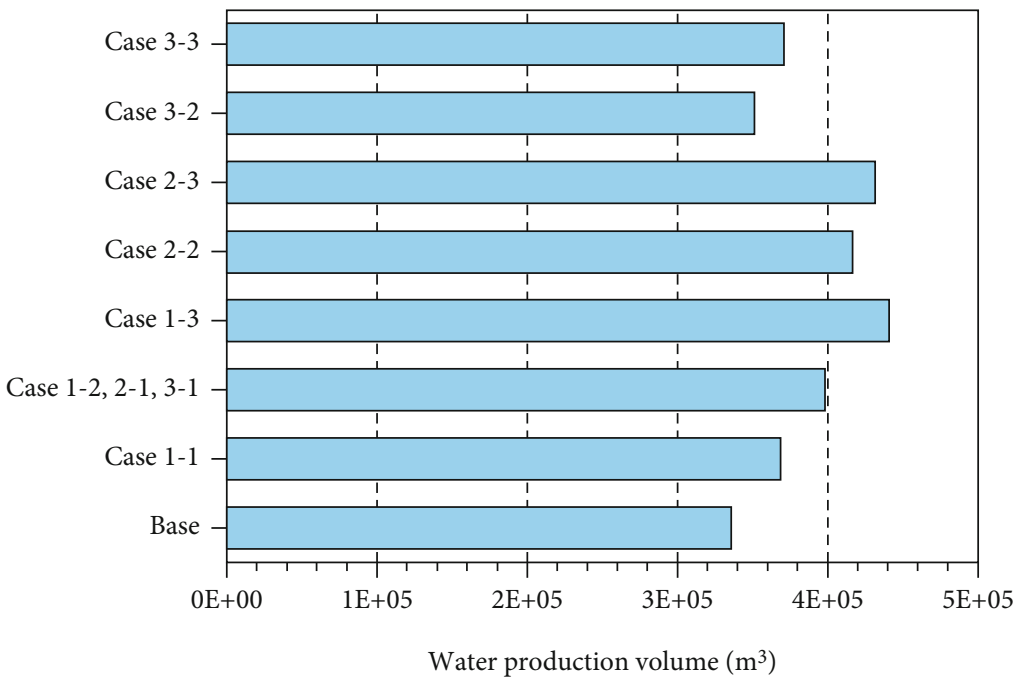

365 days

FIGURE 24: Water production volumes under different distributions of lateral branches on 365 days.

$R_{\mathrm{GW}}$ in Case 3-2 and Case 3-3 during production from $t=$ 50 days to $t=300$ days.

This can be explained by the characteristic of flow-related reservoir properties, as shown in Figure 21. The hydrate near the wellbore decomposed firstly. Larger spacing of lateral branches means shorter vertical depth of lateral branch which indicates lower efficiency of depressurization. What is more, the less spacing of lateral branches is, the stronger well interference between the branches will be which leads to the range of "static zone" increased vertically. Both the absolute criteria and relative criteria discussed earlier illustrate the obvious superiority of Case 3-1. The simulation results suggest that the vertical depth of the lateral branch has more influence on gas production than the spacing of lat- eral branches does, which should be considered in the option of geometric parameters of the multilateral well.

4.4. Summary. Figure 22 is the evolution of the gas-to-water ratio $\left(R_{\mathrm{GW}}\right)$ under all different cases which can evaluate the hydrate production efficiency. The higher $R_{\mathrm{GW}}$ indicates a small cumulative volume of produced water relative to the cumulative volume of the gas production. As shown in this figure, $R_{\mathrm{GW}}$ in base case (single vertical well) is the highest during $t=0 \mathrm{~d}$ to $t=50 \mathrm{~d}$. From $t=50 \mathrm{~d}$ to $t=300 \mathrm{~d}$ stage, $R_{\mathrm{GW}}$ in Case 2-3 with four lateral branches and Case 1-3 (the dip angle of two lateral branches are $60^{\circ}$ ) is higher than the other cases. However, after the 300-day production of $R_{G W}$ in multilateral wells, cases drop less than $R_{\mathrm{GW}}$ in base 
cases. Figure 23 shows the cumulative gas production volumes in different cases in 365 days. For the 365-day depressurization test, gas production volumes in Case 2-3 and 1-3 are bigger than the other cases increases from 2.85 $\times 10^{6}$ to $4.11 \times 10^{6}$ and $4.18 \times 10^{6} \mathrm{~m}^{3}$ compared with base case, increased by $30.5 \%$ and $31.6 \%$, respectively. Gas production volumes in Case 1-1, 1-2 (same with 2-1 and 3-1), 2-2, 3-2, and 3-3 (with four lateral branches) are increased by $12.5 \%, 21.6 \%, 26.8 \%, 5.8 \%$, and $12.8 \%$. In Figure 24 , the cumulative water production volumes under different distribution of lateral branches on 365 days are shown. Similarly, the cumulative water production volumes in Case 2-3 and 1-3 are bigger than the other cases. The value in Case 2-3 and $1-3$ are $4.31 \times 10^{5}$ and $4.41 \times 10^{5} \mathrm{~m}^{3}$.

Based on this tendency, we could draw the conclusion that the vertical depth of lateral branches has an impact on the gas production efficiency, the bigger vertical depth of lateral branches is, the larger the decompression range is. And the gas production volume increases rapidly will lead to the water production increases. Additionally, the well interference between lateral branches is essentially the superposition of the pressure drop propagation of adjacent branches. This superposition of the pressure drop can promote the decomposition of hydrate effectively. When the pressure around the production well maintains a stable state, the interference of symmetrical flow field between branches will hinder gasliquid flow with a "static zone" occurred. During this time, the well interference between lateral branches is disadvantageous for gas production.

\section{Conclusions and Suggestions}

Numerical simulations were used to evaluate the gas production performance of the reservoir by depressurization based on the geological data acquired during NGHP02 from NGHP-02-16 site in the KG basin. Then, we investigate the gas production performance of multilateral wells with different combinations of geometric parameters of multilateral branches. Based on the numerical simulations, we can draw the following conclusions:

(1) The multilateral well method can effectively increase the gas production rate from the hydrate reservoir compared with the traditional single well method. The cumulative gas production volume of a single vertical well is about $2.85 \times 10^{6} \mathrm{~m}^{3}$, while it is of the multilateral well can reach $4.18 \times 10^{6} \mathrm{~m}^{3}$ during the one-year production. The multilateral well can increase the hydrate decomposition contact area by increasing the multilateral branches based on the main wellbore which can raise the pressure and temperature transmission efficiency around the borehole. However, the hydrate decomposition rapidly will lead to the water production rate increase slightly

(2) Optimization of the geometric parameters of lateral is vital for multilateral well technology. The well interference between lateral branches, the effective influence radius of each multilateral branches, and the vertical depth of the lateral branch are the main factors which should be considered in the option of geometric parameters of the multilateral well. And the well interference between lateral branches shows different effects on gas production during different production stages. Initially, this superposition of the pressure drop can promote the decomposition of hydrate efficiently, while it will cause a "static zone" occurred which is bad to enhance the gas production efficiency in the last period. In the hydrate layer without the "static zone" occurred, the longer the vertical depth of the lateral branch, the larger decomposed range of the hydrate. However, the more the lateral branches, the faster decomposed of the hydrate with the larger the failure zones within a certain production duration which is unfavorable for lengthening the exploitation period. In this model, the dip angle of the lateral branch is greater than $30^{\circ}$, lateral branches spacing is $0 \mathrm{~m}$, and the number of branches is 2-3 are beneficial for long exploitation

(3) The site NGHP-02-16 (2546.5 m) is much deeper than the test sites at the eastern Nankai Trough $(1000 \mathrm{~m})$ and the South China Sea $(1266 \mathrm{~m})$ which is defined as ultradeepwater. So, the site NGHP-0216 is more suitable for big pressure drop. The thin thickness of the MHCZ with high gas hydrate saturation of this site determined multilateral well method could be used during the exploitation

(4) Optimization of the geometric parameters of lateral is complex in the actual field test. The optimization should also consider the indicators such as drilling cost and estimated production duration

\section{Data Availability}

The supporting data of the results in this study are available from the corresponding author upon request.

\section{Conflicts of Interest}

The authors declare that they have no conflicts of interest.

\section{Acknowledgments}

This work was supported by the Jilin Scientific and Technological Development Program (No. 20190303083SF), the National Natural Science Foundation of China (No. 41877185), the International Cooperation Key Laboratory of Underground Energy Development and Geological Restoration (No. YDZJ202102CXJD014), and the National Key Research and Development Program of China (No. 2017YFC0307304).

\section{References}

[1] H. Mimachi, S. Takeya, A. Yoneyama, K. Hyodo, and T. Takeda, "Natural gas storage and transportation within gas hydrate of smaller particle: size dependence of self- 
preservation phenomenon of natural gas hydrate," Chemical Engineering Science, vol. 118, pp. 208-213, 2014.

[2] P. Wu, Y. H. Li, X. Sun, W. G. Liu, and Y. C. Song, "Mechanical characteristics of hydrate-bearing sediment: a review," Energy\& Fuels, vol. 35, no. 2, pp. 1041-1057, 2021.

[3] D. Mahajan, C. E. Taylor, and G. Ali Mansoori, "An introduction to natural gas hydrate/clathrate: the major organic carbon reserve of the Earth," Journal of Petroleum Science and Engineering, vol. 56, no. 1-3, pp. 1-8, 2007.

[4] Z. Yin and P. Linga, "Methane hydrates: a future clean energy resource," Chinese Journal of Chemical Engineering, vol. 27, no. 9, pp. 2026-2036, 2019.

[5] L. Wang, X. Sun, S. Shen et al., "Undrained triaxial tests on water-saturated methane hydrate-bearing clayey-silty sediments of the South China Sea," Canadian Geotechnical Journal, vol. 58, no. 3, pp. 351-366, 2021.

[6] Y. Li, P. Wu, X. Sun, W. Liu, and Y. Song, "Mechanical behaviors of hydrate-bearing sediment with different cementation spatial distributions at microscales," iScience, vol. 24, no. 5, p. 102448, 2021.

[7] T. Luo, Y. Li, B. N. Madhusudhan, X. Sun, and Y. Song, "Deformation behaviors of hydrate-bearing silty sediment induced by depressurization and thermal recovery," Applied Energy, vol. 276, p. 115468, 2020.

[8] L. Yang, H. Zhang, X. Guo, R. Wei, L. Xu, and L. Sun, "The status of exploitation techniques of natural gas hydrate," Chinese Journal of Chemical Engineering, vol. 27, no. 9, pp. 2133-2147, 2019.

[9] Z. Yin, L. Huang, and P. Linga, "Effect of wellbore design on the production behaviour of methane hydrate-bearing sediments induced by depressurization," Applied Energy, vol. 254, no. 15, p. 113635, 2019.

[10] Y. Xia, T. Xu, Y. Yuan, and X. Xin, "Effect of perforation interval design on gas production from the validated hydratebearing deposits with layered heterogeneity by depressurization," Geofluids, vol. 2020, Article ID 8833884, 20 pages, 2020.

[11] Y. Yuan, Numerical Simulation on Gas Production Potential and the Geo-Mechanical Stability from Marine Natural Gas Hydrate through Depressurization, Jilin University, Changchun, 2019.

[12] Q. Chen, G. Hu, Y. Li et al., "Prospects of new technology for exploitation of offshore gas hydrate resources," Marine Geology Frontiers, vol. 36, no. 9, pp. 44-55, 2020.

[13] Y. Shi, X. Song, J. Li, G. Wang, F. YuLong, and L. Geng, "Analysis for effects of complex fracture network geometries on heat extraction efficiency of a multilateral-well enhanced geothermal system," Applied Thermal Engineering, vol. 159, p. 113828, 2019.

[14] Y. An, X. Wu, and C. Sun, Productivity Prediction Method and Application of Lateral Horizontal Gas Well, Natural gas industry, 2014.

[15] A. A. Garrouch, H. M. S. Lababidi, and A. S. Ebrahim, "A webbased expert system for the planning and completion of multilateral wells," Journal of Petroleum Science and Engineering, vol. 49, no. 3-4, pp. 162-181, 2005.

[16] S. Elyasi, "Assessment and evaluation of degree of multilateral well's performance for determination of their role in oil recovery at a fractured reservoir in Iran," Egyptian Journal of Petroleum, vol. 25, no. 1, pp. 1-14, 2016.

[17] J. Wang, W. Wang, and H. Yuan, "Analysis of drilling technology for multi-branch horizontal wells in thin oil layers at sea,"
Chemical Engineering Design Communications, vol. 45, no. 4, 2019.

[18] Y. Guo, S. Guan, Z. Liu, H. Guo, and X. Liu, "First application of multi-lateral ultra-short radius drilling in China offshore oilfields," China Offshore Oil and Gas, vol. 32, no. 5, pp. 137$144,2020$.

[19] S. J. Wilson, R. B. Hunter, T. S. Collett, S. Hancock, R. Boswell, and B. J. Anderson, "Alaska North Slope regional gas hydrate production modeling forecasts," Marine and Petroleum Geology, vol. 28, no. 2, pp. 460-477, 2011.

[20] Q. Chen, C. Liu, Y. Li, G. Hu, N. Wu, and J. Sun, "A method to determine the parameters of multi-branch horizontal well is based on the experimental simulation device of multi-branch hole technology for hydrate exploitation," China Patent, No.CN109025985 A, 2018.

[21] Y. Wan, G. Hu, N. Wu et al., "A method for productivity and reservoir stability analysis of hydrate depressurization in multilateral wells," China Patent, No.CN 109684685 A, 2018.

[22] Z. Li, X. Tian, H. Zhang et al., "A methodology of hydrate production based on multi-lateral wells," China Patent, CN110644963 A, 2020.

[23] W. Li, D. Gao, and J. Yang, "Challenges and prospect of the drilling and completion technologies used for the natural gas hydrate reservoirs in sea areas," Oil Drilling \& Production Technology, vol. 41, no. 6, pp. 681-689, 2019.

[24] P. Mao, N. Wu, F. Ning et al., "Behaviors of gas and water production from hydrate induced by depressurization with different types of wells," Natural Gas Industry, vol. 40, no. 11, pp. 168-176, 2020.

[25] S. Lv, Study on Productivity Evaluation of Multilateral Wells, Xi'an Shiyou University, 2017.

[26] C. Sun, Study of Productivity Evaluation of Multilateral Well and Optimum Design of Injection and Production, China University of Petroleum (East China), Qingdao, 2010.

[27] Y. Li, Y. Wan, Q. Chen et al., "Large borehole with multilateral branches: a novel solution for exploitation of clayey silt hydrate," China Geology, vol. 3, pp. 333-341, 2019.

[28] M. Deepak, P. Kumar, K. Singh, and U. S. Yadav, “Technoeconomic forecasting of a hypothetical gas hydrate field in the offshore of India," Marine and Petroleum Geology, vol. 108, pp. 741-746, 2019.

[29] T. S. Collett, R. Boswell, J. R. Cochran, P. Kumar, and M. Lall, "Geologic implications of gas hydrates in the offshore of India: results of the National Gas Hydrate Program Expedition 01," Marine and Petroleum Geology, vol. 58, pp. 3-28, 2014.

[30] T. S. Collett, R. Boswell, W. F. Waite et al., "India National Gas Hydrate Program Expedition 02 summary of scientific results: gas hydrate systems along the eastern continental margin of India," Marine and Petroleum Geology, vol. 108, pp. 39-142, 2019.

[31] R. Boswell, E. Myshakin, G. Moridis et al., "India National Gas Hydrate Program Expedition 02 summary of scientific results: numerical simulation of reservoir response to depressurization," Marine and Petroleum Geology, vol. 108, pp. 154-166, 2019.

[32] J. A. Priest, J. L. Hayley, W. E. Smith, P. Schultheiss, and J. Roberts, "PCATS triaxial testing: Geomechanical properties of sediments from pressure cores recovered from the Bay of Bengal during expedition NGHP-02," Marine and Petroleum Geology, vol. 108, pp. 424-438, 2019.

[33] J. S. Lin, S. Uchida, E. M. Myshakin, Y. Seol, J. Rutqvist, and R. Boswell, "Assessing the geomechanical stability of 
interbedded hydrate-bearing sediments under gas production by depressurization at NGHP-02 Site 16," Marine and Petroleum Geology, vol. 108, pp. 648-659, 2019.

[34] J. Jang, W. F. Waite, L. A. Stern, T. S. Collett, and P. Kumar, "Physical property characteristics of gas hydrate-bearing reservoir and associated seal sediments collected during NGHP-02 in the Krishna-Godavari Basin, in the offshore of India," Marine and Petroleum Geology, vol. 108, pp. 2648172, 2018.

[35] E. M. Myshakin, Y. Seol, J. S. Lin, S. Uchida, T. S. Collette, and R. Boswell, "Numerical simulations of depressurizationinduced gas production from an interbedded turbidite gas hydrate-bearing sedimentary section in the offshore India: Site NGHP-02-16 (Area-B)," Marine and Petroleum Geology, vol. 108, pp. 619-638, 2019.

[36] Y. Yuan, T. Xu, X. Xin, and Y. Xia, "Multiphase flow behavior of layered methane hydrate reservoir induced by gas production," Geofluids, vol. 2017, Article ID 7851031, 15 pages, 2017.

[37] J. Yoneda, M. Oshima, M. Kida et al., "Permeability variation and anisotropy of gas hydrate-bearing pressure-core sediments recovered from the Krishna-Godavari Basin, offshore India," Marine and Petroleum Geology, vol. 108, 2019.

[38] Y. Konno, A. Kato, J. Yonedab et al., "Numerical analysis of gas production potential from a gas-hydrate reservoir at Site NGHP-02-16, the Krishna-Godavari Basin, offshore IndiaFeasibility of depressurization method for ultra-deepwater environment," Marine and Petroleum Geology, vol. 108, pp. 731-740, 2019.

[39] M. E. Holland, P. J. Schultheiss, and J. A. Roberts, "Gas hydrate saturation and morphology from analysis of pressure cores acquired in the Bay of Bengal during expedition NGHP-02, offshore India," Marine and Petroleum Geology, vol. 108, pp. 407-423, 2019.

[40] S. Uchida, J. S. Lin, E. M. Myshakin, Y. Seol, and R. Boswell, "Numerical simulations of sand migration during gas production in hydrate-bearing sands interbedded with thin mud layers at site NGHP-02-16," Marine and Petroleum Geology, vol. 108, pp. 639-647, 2019.

[41] G. Moridis, "User's manual for the hydrate v1.5 option of TOUGH+ v1.5: a code for the simulation of system behavior in hydrate-bearing geologic media," Technical Report, 2014, LBNL-6869E.

[42] S. Zhou, F. Sun, X. Zeng, and M. Fang, "Application of multilateral wells with limited sand production to heavy oil reservoirs," Petroleum Exploration and Development, vol. 35, no. 5, pp. 630-635, 2008.

[43] M. T. van Genuchten, "A closed-form equation for predicting the hydraulic conductivity of unsaturated soils," Soil Science Society of America Journal, vol. 44, no. 5, pp. 892-898, 1980.

[44] H. Stone, "Probability model for estimating three-phase relative permeability," Journal of petroleum technology, vol. 22, no. 2, pp. 214-218, 1970.

[45] Z. Yin, G. Moridisc, H. K. Tan, and P. Linga, "Numerical analysis of experimental studies of methane hydrate formation in a sandy porous medium," Applied Energy, vol. 220, pp. 681-704, 2018.

[46] Z. Yin, G. Moridis, Z. R. Chong, H. K. Tan, and P. Linga, "Numerical analysis of experimental studies of methane hydrate dissociation induced by depressurization in a sandy porous medium," Applied Energy, vol. 230, pp. 444-459, 2018. 